\title{
Orígenes del 'New Urbanism' y su influencia en los paradigmas de desarrollo urbano contemporáneos
}

\section{Origins of 'New Urbanism' and its influence on the paradigms of contemporary urban development}

DOI: 10.17981/mod.arq.cuc.18.1.2017.01

Artículo. Fecha de recepción: 10/05/2017 Fecha de aceptación: 23/07/2017

\section{Sander Said Chávez Martínez}

Universidad del Norte (Colombia)

sanderc@uninorte.edu.co

\author{
Walberto Lucas Badillo Jimenez \\ Universidad del Norte (Colombia) \\ walbertob@uninorte.edu.co
}

Para citar este artículo:

Chávez, S. y Badillo, W. (2017). Orígenes del 'New Urbanism' y su influencia en los paradigmas de desarrollo urbano contemporáneos. MODULO ARQUITECTURA-CUC, vol. 18, no. 1, pp. 9-38. DOI: 10.17981/mod.arq.cuc.18.1.2017.01

\section{Resumen}

Las ciudades herederas de las problemáticas del modernismo industrializado fordista se han sometido a procesos de reinvención desde un enfoque teórico postmoderno "sostenibilista" que valida la necesidad de construcción de un nuevo paradigma urbano acorde con los intereses ciudadanos de finales del siglo XX. Las premisas de este nuevo urbanismo constituyen el cimiento discursivo de los movimientos de construcciones verdes que se han extendido a escala global, pero que en ámbitos iberoamericanos carecen de un proceso de adaptación acorde a las realidades urbanas locales, y, en lugar de eso, han adoptado estándares norteamericanos, concebidos en condiciones socioeconómicas diferentes. Por tal razón, se plantea la reflexión de la influencia que ha tenido el 'New Urbanism' en propuestas urbano-arquitectónicas implementadas recientemente en el caribe colombiano, en contraste con los primeros exponentes en Estados Unidos; esta deliberación se hace desde lo conceptual hasta lo constructivo, transitando por el paso obligado de su manifestación en el mercado inmobiliario.

Palabras claves: construcción verde, desarrollo urbano, Nuevo Urbanismo, urbanización

\section{Abstract:}

There exist cities which have inherited issues from the industrialized modernism, these have been analyzed by processes of reinvention by using a post-modernist sustainability-based theoretical approach that justifies specific requirements to create a new urban paradigm, in accordance with the interests of citizens in the late twentieth century. With regard to the premises of the mentioned design movement these have enhanced environmentally friendly habits throughout the world, conversely Ibero-American areas does not have a complete performance of adaptation according with its local conditions, instead of this American standards of construction, conceived in different economic conditions, have been employed; hence it is relevant to point out views form New Urbanism have influenced the architectural proposals in the Caribbean Region of Colombia by using not only conceptual features but also building procedures addressed to the estate market.

Keywords: green Building, New Urbanism, Urban development, Urban planning 


\section{INTRODUCCIÓN}

Las disciplinas como el urbanismo y el diseño urbano requieren constantemente la revisión y actualización de referentes teóricos y proyectuales precisos, necesarios para gestionar la permanente evolución de sus imaginarios idealizados en los procesos de construcción de la ciudad. Tales cambios deben emerger como alternativas reales que procuren dar solución a las clásicas problemáticas de los centros urbanos, especialmente amplificadas en proporción con el crecimiento escalar que estas alcanzan, tanto por la ocupación muchas veces irracional de extensas áreas de territorio, como por los procesos lógicos de densificación derivados de la complejidad interna que dan dinamismo y vida a una aglomeración urbana.

Si bien uno de los éxitos de la raza humana ha sido la ciudad como culmen materializado del saber de las grandes civilizaciones, también, en su proceso evolutivo, se han presentado deseconomías que validan la construcción de nuevos paradigmas sociales, productivos y de intervención espacial que han dado paso a manifestaciones urbanas cada vez más efectivas en su propósito de dar cobijo a las sociedades con carácter emergente.

La ciudad industrializada engendrada en medio del modelo productivo fordista sufrió importantes críticas a finales del siglo XX, dando pie a planteamientos de desarrollo urbano completamente contradictorios a la estandarización, la producción en masa y a la expansión indiscriminada de las manchas urbanas que sobrepasaban la capacidad de gestión de muchas estructuras gubernamentales y que, a su vez, superaban la comprensión tradicional o clásica de la ciudad. En su lugar fueron emergiendo alternativas de transformación que argumentan la compacidad, la densificación, el eclecticismo, la diversidad y lo exclusivo como elementos necesarios en la nueva realidad urbana; ejemplos de esto son, el Landscape Urbanism y el New Urbanism, tendencias que surgieron en Estados Unidos en la década de los 80 del siglo XX y lograron influenciar a través de un marco teórico bastante amplio las decisiones de la arquitectura y el urbanismo desde finales del siglo pasado hasta la actualidad (Heins, 2015).

El ámbito colombiano y, en general, el latinoamericano se han visto influenciados fundamentalmente por el New Urbanism, ya que ha tenido mayor difusión a través del paradigma sostenibilista del postmodernismo de finales de siglo $X X$, más específicamente, enmarcado dentro de la línea de disciplinas y corrientes de pensamiento que han puesto en el escaparate la arquitectura y el urbanismo 'verde', los cuales abrieron el camino a unos sistemas de valoración y certificación de edificaciones y proyectos urbanos, como el sistema: 'Leadership in Energy \& Environmental Design' (L.E.E.D.) propuesto por el United States Green Building Council (USGBC). Muy a pesar de que las realidades urbanas del ámbito anglosajón han sido distintas al de Latinoamérica, se han 
adoptado premisas del nuevo urbanismo; en ocasiones, sin una adecuada traducción o adaptación al contexto sociocultural de las metrópolis hispanas (Acevedo, Vásquez y Ramírez, 2012).

Teniendo en cuenta lo descrito anteriormente, en el presente artículo se expone un análisis de los principales argumentos que dan soporte a la aparición y consolidación del nuevo urbanismo, haciendo un recuento de los valores que legitiman su idoneidad en ciertos escenarios; además, se estudian y comparan dos casos de proyectos urbanos a la luz de los principios rectores del paradigma en cuestión a modo de contraste entre su implementación basada en la realidad anglosajona y su contextualización en el ámbito colombiano.

\section{Colapso de la metrópolis industrializada de Norteamérica}

Durante la primera mitad de los años 70 , a causa de las crecientes tensiones entre los países del medio oriente, principalmente aquellos productores de petróleo con ideologías revolucionarias y contrarios a la ocupación israelí en territorio palestino, acordaron conjuntamente, como miembros de la OPEP, el alza de los precios del barril de crudo a casi tres veces su valor tradicional. Esto a modo de presión para los países industrializados de occidente, cada vez más dependientes de la economía basada en los hidrocarburos (Sablich, 2010).
De forma casi simultánea, se cerraba el ciclo de la guerra de Vietnam que, desde los años 50, sacudía internamente la sociedad norteamericana, dividida entre el apoyo y el rechazo a dicho conflicto bélico, el cual dejó veteranos que protagonizaron movimientos de protesta en contra de las decisiones gubernamentales del momento (Appy, 2008). Ambas situaciones se dieron en medio de un ambiente de crítica a las estructuras sociales preestablecidas suscitado por el movimiento de la Contracultura de la década de los 60 que se levantaba como antagonista al paradigma de la vida americana ideal.

En el marco de este proceso de reforma al paradigma de la ciudad, cultura productiva y estructuras sociales se gesta el post-fordismo como alternativa dispar del criterio de la estandarización y masificación, que apeló a la especialización, la diversificación y el eclecticismo tanto en los procedimientos productivos, como en las formas de entender la ciudad y el prototipo de familia ideal americana. Esta situación motivó la reflexión acerca de la idoneidad del modelo de ocupación del territorio disperso, caracterizado por los extensos barrios residenciales en baja densidad de clase media con tipologías de vivienda estandarizadas. Sumado a esto, se hicieron cada vez más evidentes los nefastos resultados de la industrialización de las grandes metrópolis que, a modo de fuerza centrífuga, "arrojaron" gran cantidad de población de clase media a la dispersión urbana, extendiéndose en los territorios aledaños, aun por 
fuera de las jurisdicciones de las ciudades generadoras de tal dinamismo. De esta forma, se gestó gradualmente la aparición de nuevos centros urbanos a partir de la descompensación poblacional de los centros originarios, en un fenómeno que algunos autores describirían como la contra-urbanización (Arroyo, 2001).

La conjunción de estos cinco elementos y sus significados sociales, es decir, la crisis petrolera que puso en evidencia la cada vez mayor dependencia del mundo occidental a los combustibles fósiles, la crítica a los paradigmas de gobierno tras la postguerra de Vietnam, la contracultura como detracción a las estructuras sociales y familiares tradicionales, sumados a unos fenómenos de promo- marco del post-fordismo, además de la manifestación avasalladora de la dispersión urbana evidenciada por los cambios en la red de las principales metrópolis bajo el fenómeno de la contra-urbanización del siglo XX, validaron el cuestionamiento del modelo de ocupación del territorio vigente en aquel momento y abrió las puertas a que nuevas alternativas de urbanización fueran puestas en consideración para ser implementadas. Es decir, que, ante esta suma de sucesos provenientes desde distintos frentes que suponen a manera de crisis el colapso de la metrópolis industrializada norteamericana, era apenas válido proponer un nuevo modelo de urbanismo que emulara como tabla de salvación a los pre-urbanistas utópicos socialistas de mediados del siglo XIX en Europa.

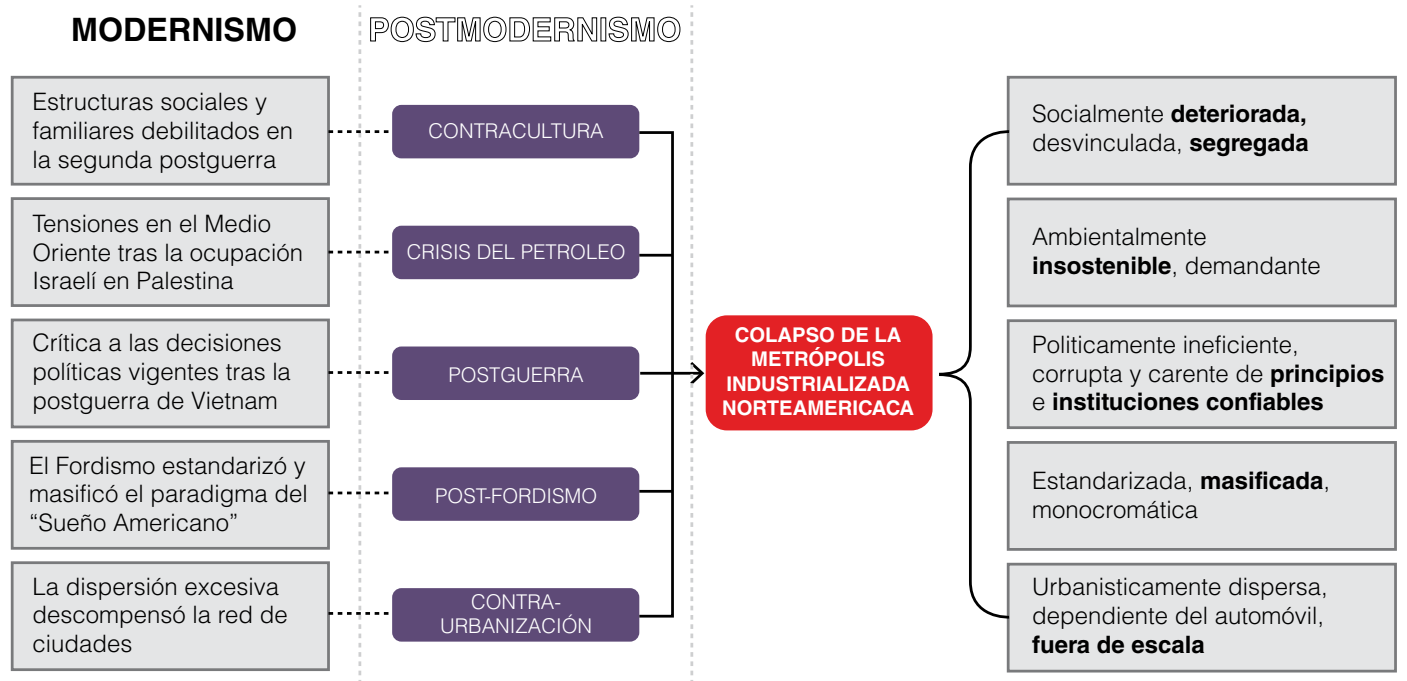

Fig. 1. Condiciones de partida del 'New Urbanism'.

Fuente: elaboración propia basado en Blasco (2015). 
Históricamente, el surgimiento de una nueva manera de afrontar el urbanismo presupone que las formas inmediatamente anteriores estaban erróneas o han agotado sus virtudes hasta el punto de llegar a la obsolescencia, y, para ello, se construyó todo un marco teórico y conceptual que cimentaba el discurso de que la ciudad resultante del fordismo carecía de los niveles de habitabilidad adecuados por diferentes y obvias razones. El predominio del automóvil posibilitó el crecimiento disperso de las ciudades y, en paralelo con dicha expansión física, la calle perdía el carácter de espacio público generador de comunidad e identidad y susceptible de ser apropiado. En su lugar, surge la vía como un área de simple circulación, indivi- dualista, neutral, sobria y que difícilmente provoca sentimientos de pertenencia o territorialidad entre los que la transitan (Blasco, 2015) (Gunn, 2005).

También es pertinente sumar a lo anterior, la discusión que se ha adelantado desde el ámbito de la economía urbana, en la que se han planteado los interrogantes de que si el crecimiento de las ciudades puede ser ilimitado o si una aglomeración excesiva no solo brinda las ventajas de eficiencia y productividad propias de la concentración sino que además trae consigo una serie de desventajas o deseconomías que parecen incrementarse en relación directa con el crecimiento de las metrópolis, viéndose manifiestas en situaciones como el colapso de las redes

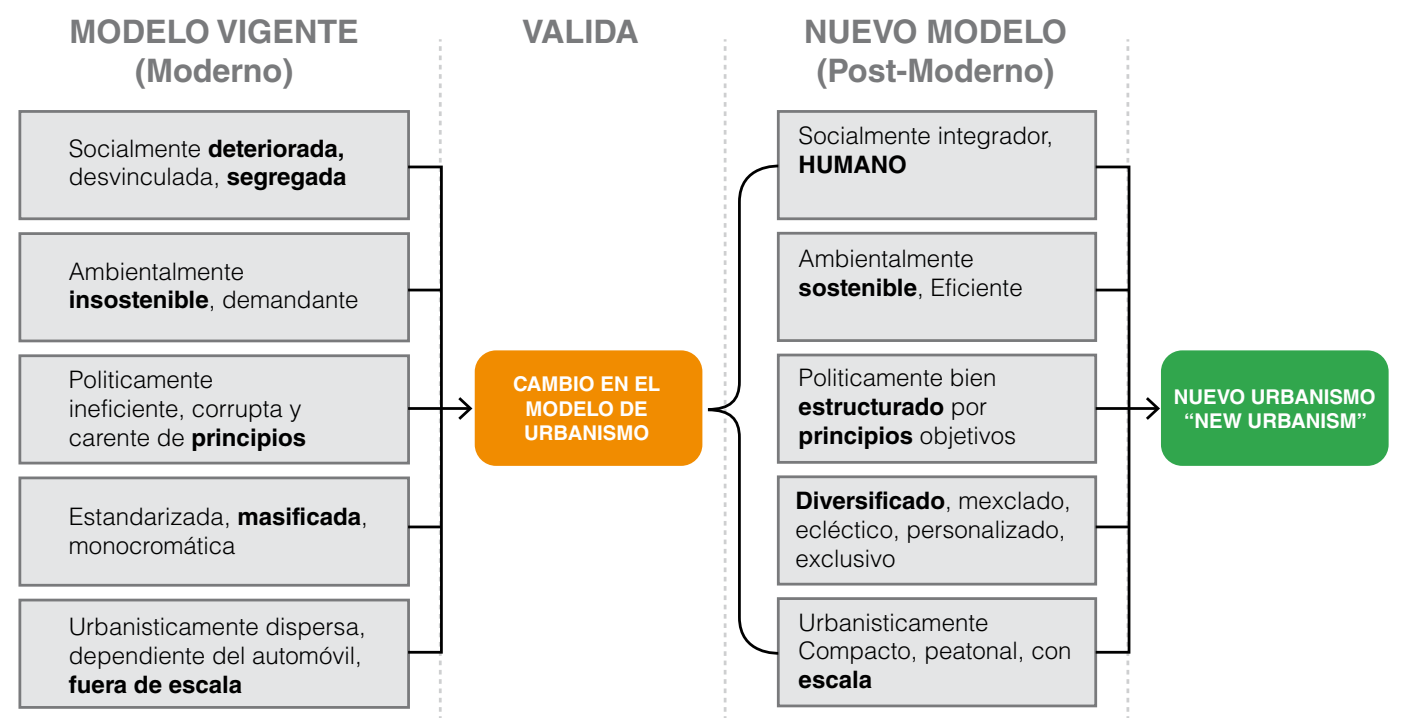

Fig. 2. Premisas del nuevo modelo de urbanismo.

Fuente: elaboración propia basado en Blasco (2015). 
de infraestructura, la congestión vial, la inseguridad urbana, la polución atmosférica, la sobrecarga a los sistemas de abastecimiento hídrico, tanto en el ámbito urbano como en el rural, para la producción de alimento, etcétera (Camagni, 2004) (Polèse, 1998) (Manrique, 2006). Este cúmulo de evidencias validó la construcción de un andamiaje argumentativo en contra del modelo de ciudad metrópolis imperante en Norteamérica, pero igualitariamente estructural en la concepción de esa nueva versión del urbanismo.

Dentro de esta literatura de soporte teórico-conceptual están las reconocidas obras de diferentes autores, como Kevin en la que se resalta la comprensión de la ciudad desde la perspectiva del habitante y su forma de leer lo urbano; Jane Jacobs, con Muerte y vida de las grandes ciudades americanas (Jacobs, 1961), en el que se presenta una directa oposición a las tendencias urbanizadoras apelando a aspectos como la seguridad, la diversidad y la habitabilidad urbana, hilvanado con el discurso postmoderno de la decadencia de lo vigente versus el renacer de lo positivo de lo antiguo; y Rob Krier, con El espacio urbano: proyectos de Stuttgart, en el que expone las características de los componentes del espacio, desde una óptica esteticista de la experiencia del peatón con la escala de lo construido (Krier, 1976).

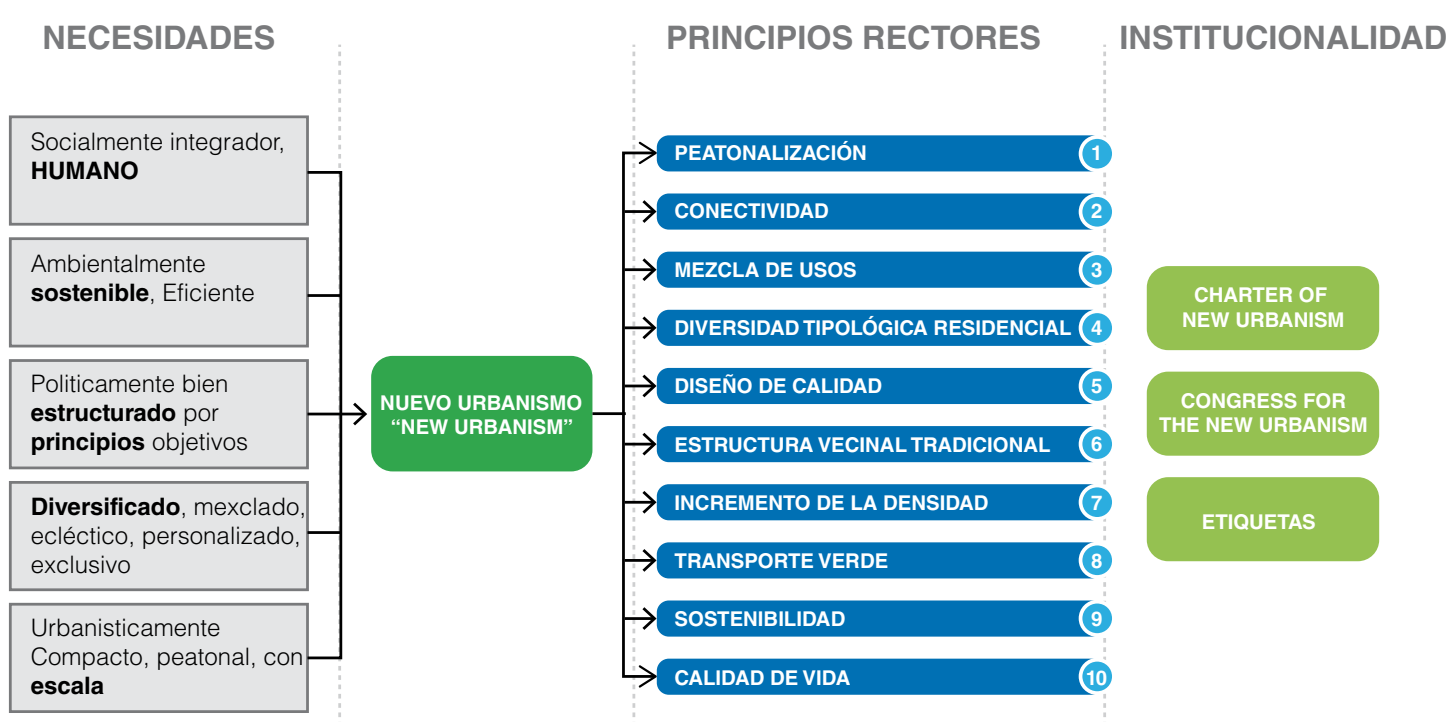

Fig. 3. Principios rectores del 'New Urbanism'. 


\section{La Carta del nuevo urbanismo y el Congreso del nuevo urbanismo}

Como reacción a las problemáticas que el funcionalismo y el racionalismo moderno generaron en las ciudades, surgen discursos como el de $\mathrm{Krier}^{1}$, que pueden ser enmarcados dentro del fenómeno del postmodernismo, el cual está caracterizado por la emulación a patrones tradicionales, a nivel arquitectónico, a escala urbana, territorial y regional, permitiendo la consolidación de expresiones vernáculas y hasta neoclásicas, pero reinterpretadas bajo la óptica racional del siglo XX (Busquets y Correa, 2006).
La escala de la ciudad también supone una problemática que se enfrenta teóricamente con los distintos postulados que dieron soporte al 'New Urbanism', y que, precisamente, quedó en evidencia cuando la crisis energética de los 70 , debido a la escasez de petróleo, supuso el colapso de las metrópolis, que por su talla y configuración metabólica no podrían funcionar cabalmente sin los combustibles fósiles. Ante esto, se propuso que las comunidades fueran de escalas más pequeñas, más fácilmente transitables por medios más humanos o menos mecánicos, con mezcla de usos que generaran relaciones funcionales más complejas y que, a su vez, generarían metabolismos urbanos cada vez menos demandantes de recursos no renovables (Blasco, 2015).
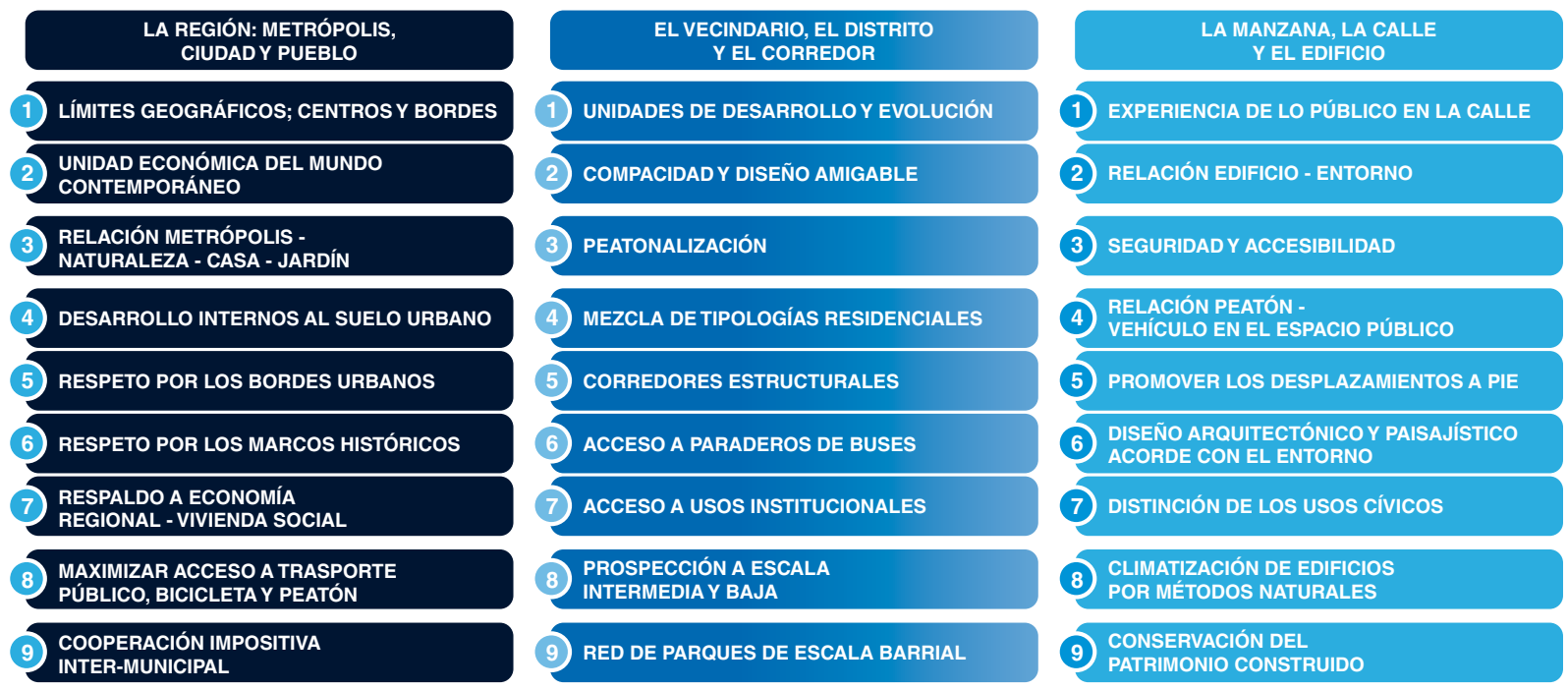

Fig. 4. Principios del 'New Urbanism” aplicados en las diferentes escalas. Fuente: Congress for the New Urbanism (2013) 
Con la Carta del nuevo urbanismo (Congress for the New Urbanism - CNU, 2001)se consolidan completamente los principales postulados que emergieron en la segunda mitad del siglo XX, y conscientemente se propone "The New Urbanism", el cual se reivindica como un movimiento de reforma a las ciudades. En ese documento se argumenta la necesidad de reestructuración de las políticas públicas y el desarrollo práctico, la planeación urbana y el diseño en las distintas escalas en las que se ocupa el territorio, partiendo desde lo regional y aproximándose, en última instancia con el ejercicio del diseño urbano, a la configuración de la calle y la unidad edificatoria, por ejemplo:

\section{La región: metrópolis, ciudad y centros urbanos}

Las regiones metropolitanas son espacios finitos con bordes geográficos determinados por la topografía, cuerpos de agua, líneas costeras, fincas, reservas naturales regionales y cuencas hidrográficas.

- La región metropolitana es una unidad económica fundamental en el mundo contemporáneo. La cooperación gubernamental, la política pública, la planeación física y las estrategias económicas deben reflejar esta nueva realidad.
- La metrópolis tiene una relación necesaria y frágil con su hinterland agrario y paisajes naturales. Dicha relación se da desde lo económico, lo cultural y lo ambiental; los suelos para cultivo llegan a ser tan importantes para la metrópolis como el jardín lo es para una vivienda.

- Los patrones de desarrollo no deberían difuminar o erradicar los bordes de la metrópolis. Los procesos de desarrollo de "vacíos" (tanto funcionales como físicos) en áreas urbanas permite conservar los recursos ambientales, las inversiones y el tejido social, a la vez que recupera áreas marginales o abandonadas. Es por ello que se requiere que en las regiones se desarrollen estrategias para promover la rehabilitación urbana sobre la expansión.

- Donde corresponda, los nuevos desarrollos contiguos a los bordes urbanos deberían estar organizados como vecindarios o distritos, y ser integrados con la trama urbana existente. Los desarrollos no contiguos deben ser organizados como centros o villas con sus propios límites y ser planificados para que exista un balance entre residencia y trabajo, de modo que no sean solo suburbios dormitorios.

- Los desarrollos y redesarrollos de ciudades y pueblos deben respetar las tramas urbanas históricas, los precedentes y los bordes (Congress for the New UrbanismCNU, 2013). 
En este contexto, el nuevo urbanismo se define como el enfoque de la planeación y el desarrollo, basado en los principios con los que han sido construidos los centros urbanos en los últimos siglos, es decir, donde las manzanas y calles son aptas para caminar, la vivienda y el comercio se ubican en estrecha proximidad y el espacio público es accesible a todos (Congress for the New Urbanism, 2013); por tanto, la experiencia del peatón en la ciudad adquiere prelación, y, por ello, se promueve la peatonalización de los espacios urbanos en los proyectos que se etiquetan como pertenecientes al nuevo urbanismo. Además, éstos no deben ser dependientes del automóvil para su disfrute, por lo que se concluye que, para lograrlo, es necesario que exista una mezcla de usos de suelo (Speck, 2013).

Adicional a la mezcla de usos, se propone la diversidad de tipologías residenciales como alternativa de desarrollo más eficiente, contrariando la masificación de la vivienda de los hermanos Levitt en el fenómeno denominado "fordismo inmobiliario" (Glaeser, 2011) (Kelbaugh, 1997), promoviendo, además, una interacción más efectiva entre familias de distintas capacidades adquisitivas en una misma zona; así mismo, se abre camino a una sana competencia en las calidades en los diseños, tanto de lo arquitectónico como de los espacios urbanos. Estas ideas se compilan de manera recurrente en los SmartCodes (códigos inteligentes), cuyo propósito es determinar los parámetros que rigen las configuraciones urbanas, desde lo más denso o urbano hasta lo más disperso o rural. Basándose en la metodología de análisis del transecto, se establecen las ordenanzas y el direccionamiento de los desarrollos urbanos en el territorio en todas las escalas (Duany, Sorlien y Wright, 2003).

Parte importante de lo que se planifica en los SmartCodes es el tema normativo de la densidad, y en el nuevo urbanismo se procura el incremento de la misma para facilitar la conectividad entre los sectores, preferiblemente con recorridos que se puedan hacer a pie o que, en su defecto, se pueda acoger a algún medio de transporte de cero emisiones, como la bicicleta; y a nivel de región, lograr la construcción de una red de trenes que favorezcan los desplazamientos, desde lo más disperso o rural hasta lo más denso, y, de igual manera, al interior de las ciudades y en los sectores más céntricos. Con lo anterior se pretende cumplir con el principio contemporáneo de sostenibilidad, que busca generar el menor impacto en los desarrollos urbanos y en la operación de estos, apelando al uso de tecnologías amigables con el medio ambiente, es decir, procurando ser más eficientes en términos energéticos, contribuyendo a reducir el consumo de combustibles fósiles, a la vez que se promueve caminar más diariamente y conducir menos. Estas disposiciones deben redundar en la mejora de la calidad de vida de los habitantes, no solo en términos de salud, sino también en lo positivo de su experiencia vivencial dentro de la ciudad (newurbanism. org, 2017). 


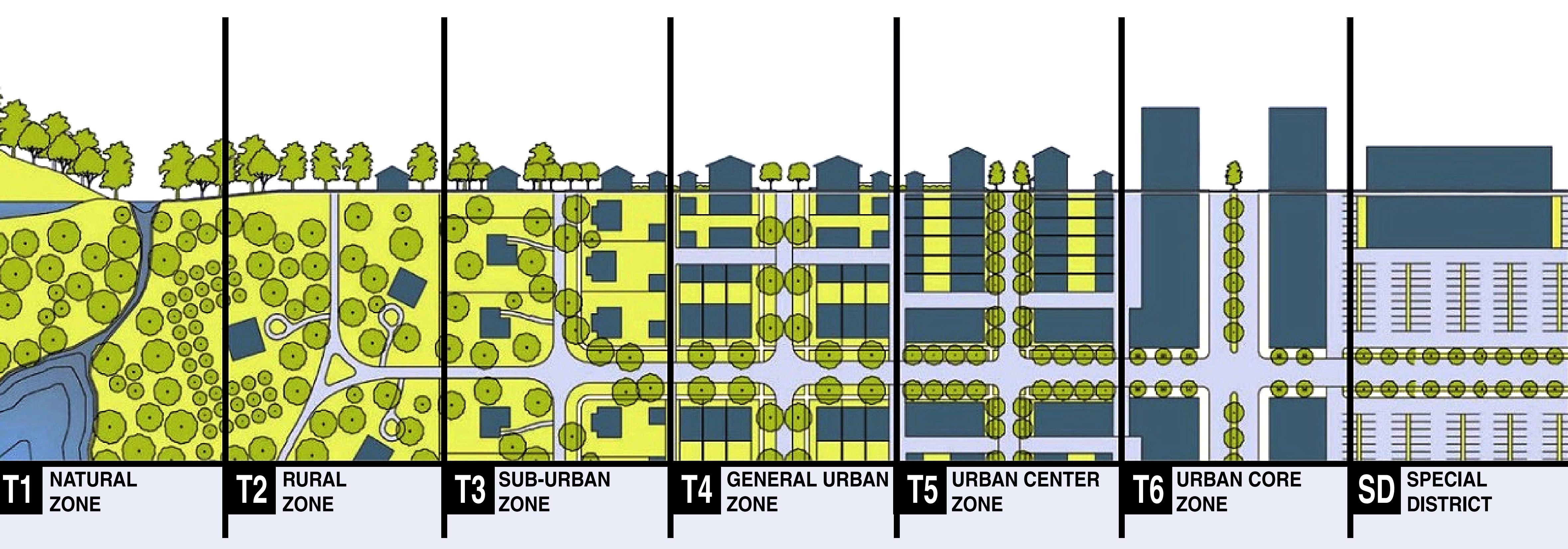




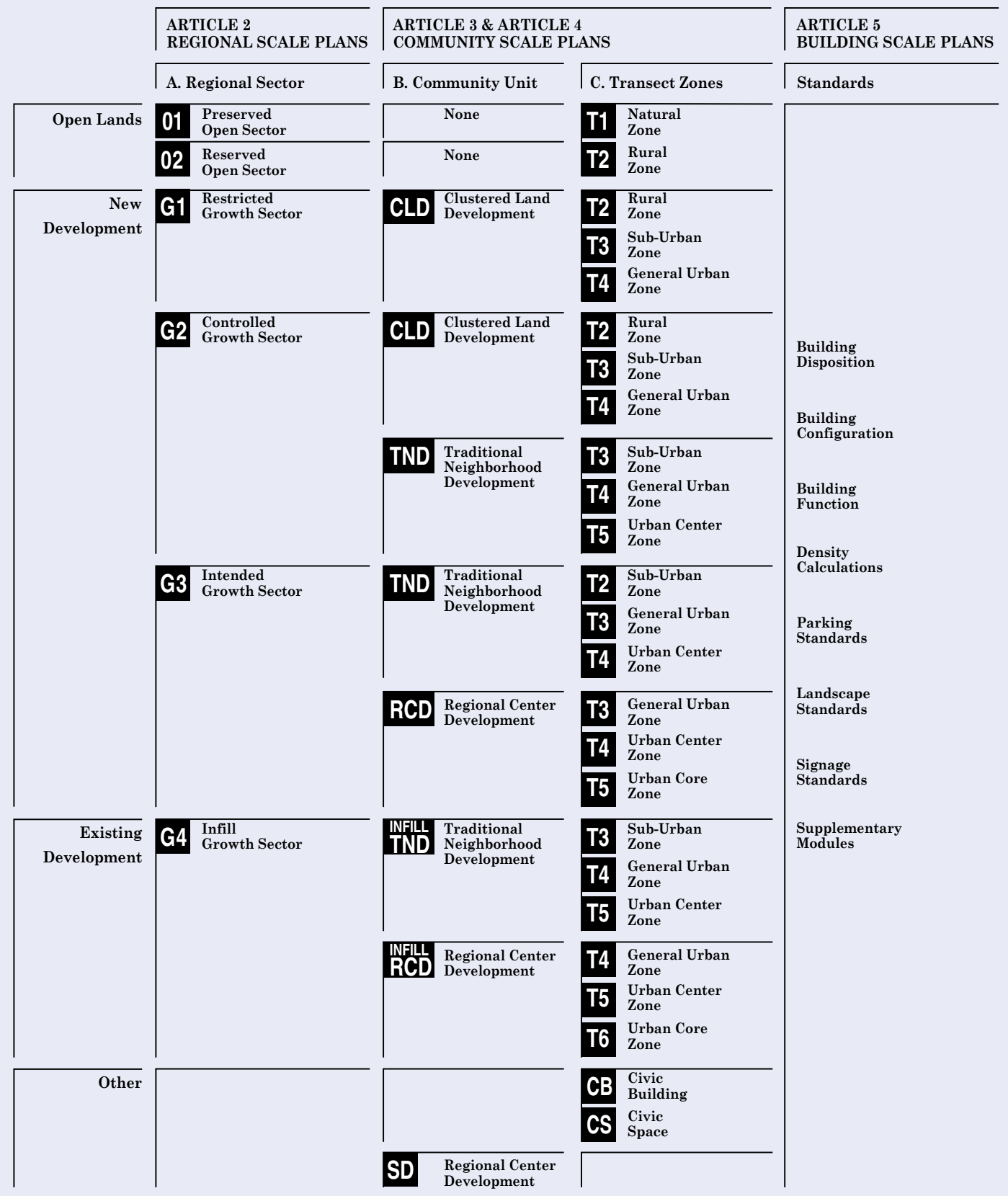

Fig. 6. Bosquejo de la estructura de un SmartCode.

Fuente: Duany, Sorlien y Wright (2003). 
La influencia del 'New Urbanism' en L.E.E.D.-ND

Estos principios rectores y la necesidad de objetivar los juicios de valoración de las distintas propuestas de diseño y construcción de edificios y barrios hicieron posible la aparición de sistemas estandarizados de calificación de los proyectos, de modo que se permitieran etiquetar, categorizar y promover los desarrollos inmobiliarios a través de certificaciones de calidad o sostenibilidad. De ahí que el consejo estadounidense de construcción verde, o USGBC por sus siglas en inglés, heredero del paradigma ecologista del 'New Urbanism', desarrollara el sistema L.E.E.D., que certifica el liderazgo en diseño energético y ambiental para distintas categorías de proyectos en diversas escalas de intervención.

En el caso de los vecindarios, se certifican con la norma L.E.E.D.-ND, que evalúa 6 ejes primarios: ubicación inteligente y conectividad; malla urbana y diseño; edificaciones e infraestructuras verdes; innovación; prioridad

SMART LOCATION AND LINKAGE
NEIGHBORHOOD PATTERN \& DESIGN
GREEN INFRASTRUCTURE \& BUILDINGS
INNOVATION
REGIONAL PRIORITY CREDITS INTEGRATIVE PROCESS CREDITS

Fig. 7. Tarjeta de puntaje de un proyecto evaluado en L.E.E.D.-ND. 
NEIGHBORHOOD PATTERN \& DESIGN

NPDc1
NPDc10
NPDc11
NPDc12
NPDc13
NPDc14
NPDc15
NPDc2
NPDc3
NPDc4
NPDc5
NPDc6
NPDc7
NPDc8
NPDc9

NPDc1

Walkable streets

Access to recreation facilities

Visitability and universal design

Community outreach and involvement

Local food production

Tree-lined and shaded streets

Neighborhood schools

Compactc development

Mixed-use heighborhood centers

Mixed-income diverse communities

Reduced parking footprint

Street network

Transit facilities

Transportation demand management

Access to civic and public space
$8 / 12$

31 OF 44

$1 / 11$

$0 / 1$

$0 / 2$

$1 / 1$

$2 / 2$

$1 / 1$

$5 / 6$

$4 / 4$

$6 / 7$

$0 / 1$

$0 / 2$

$1 / 1$

$1 / 2$

$1 / 1$

Fig. 8. Ejemplo de puntuación detallada en L.E.E.D.-ND; eje: malla urbana y diseño. 
regional; y procesos de integración. Estos ejes, a su vez, se desglosan en varios indicadores con los cuales se mide el grado de aplicación de los principios de la construcción verde; por ejemplo, el de malla urbana y diseño cuenta con 15 indicadores como la 'transitabilidad' peatonal (Speck, 2013), facilidad de acceso a espacios recreativos, universalidad del diseño, participación ciudadana, producción local de alimentos, arborización y nivel de sombra en las vías, presencia de escuelas en el vecindario, compacidad, mezcla de usos, mezcla de familias de distintos ingresos, reducción de la huella de parqueos, red vial, facilidad de tránsito, gestión de la demanda del transporte y acceso a espacios públicos cívicos. Así mismo, cada uno de estos indicadores cuenta con diversas variables que ayudan a evaluar en detalle la funcionalidad del diseño y el modo de operación de la comunidad.

\section{Seaside, Florida}

Durante los años 80, se empezó a incursionar con el diseño, promoción y construcción de Seaside, una comunidad ubicada sobre la costa del golfo de México, en Fort Walton Beach, Florida. En este proyecto se buscó la implementación de todos los criterios de planificación urbana que emergieron con este nuevo paradigma social y económico que se fraguaba en Norteamérica durante la última década. El argumento con el que se promovió Seaside fue que este nuevo desarrollo emulaba el carácter histórico de las ciudades sureñas de Estados Unidos, proponiendo trazados urbanos típicos de los asentamientos americanos tradicionales tanto en forma como en la zonificación de los usos del suelo, la cual se normalizó a través de un código de urbanismo.

El diseño del proyecto propone un centro con espacios públicos, usos comerciales y actividades cívicas alrededor del cual se distribuyen las manzanas de uso residencial con distintas tipologías edificatorias definidas en el código urbano de Seaside. En el trazado del proyecto claramente se definen dos diagonales que pretenden la conexión directa de los sectores más alejados de la urbanización hacia la plaza central, estos ejes articulan la movilidad y dan cobijo a usos educativos, comerciales y, principalmente, a los espacios recreativos. El código urbano que se definió para Seaside establece ocho tipos de edificaciones diferentes, en algunos casos viviendas de poca altura y aspecto campestre, pero en otras zonas se emplazan edificios de mayor talla con fines comerciales o usos educativos, religiosos, etc. 


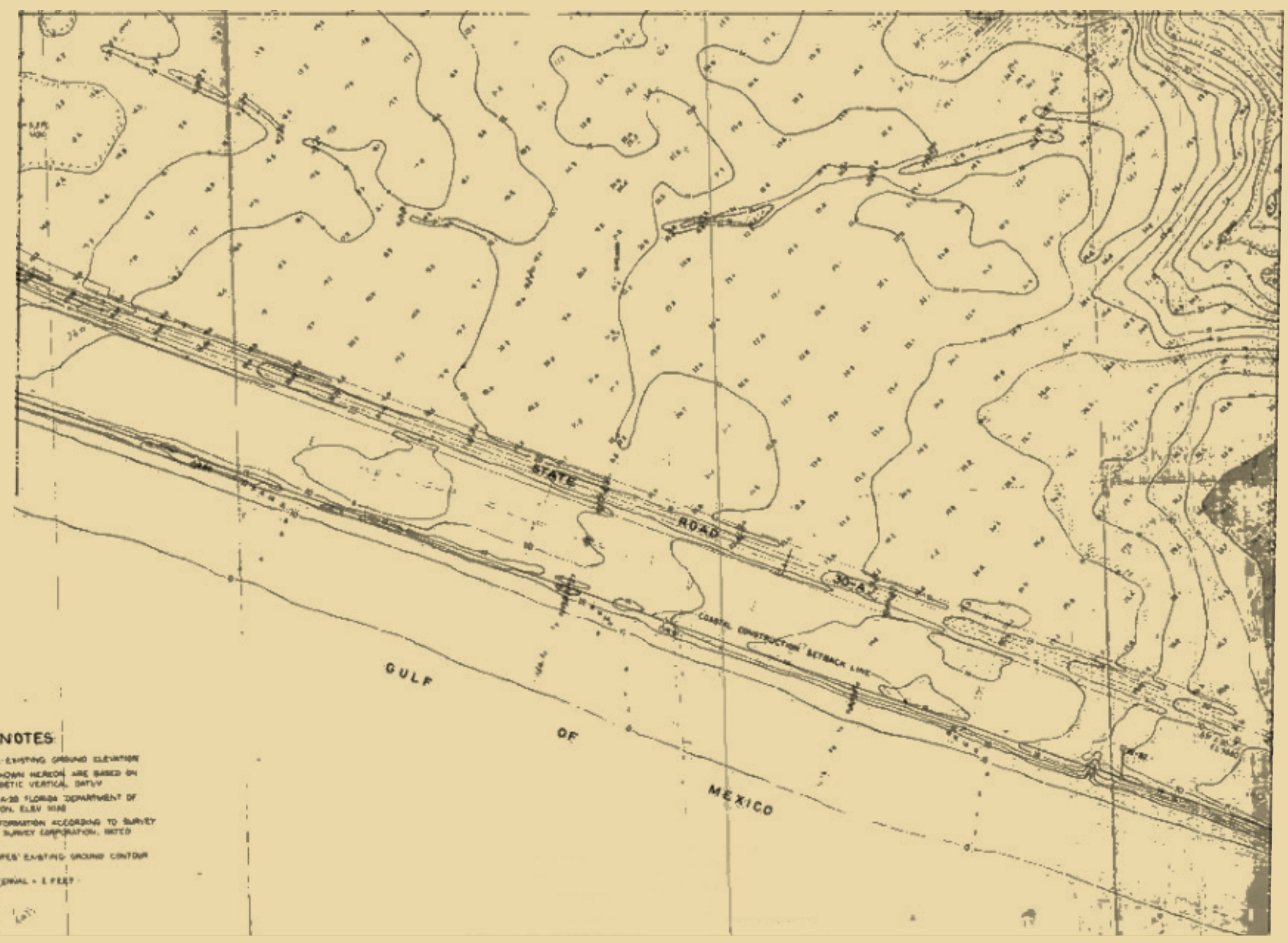

Fig. 9. Plano topográfico de Sea Grove, terreno en el que se desarrolló Seaside.

Fuente: University of Notre Dame (s.f.). 


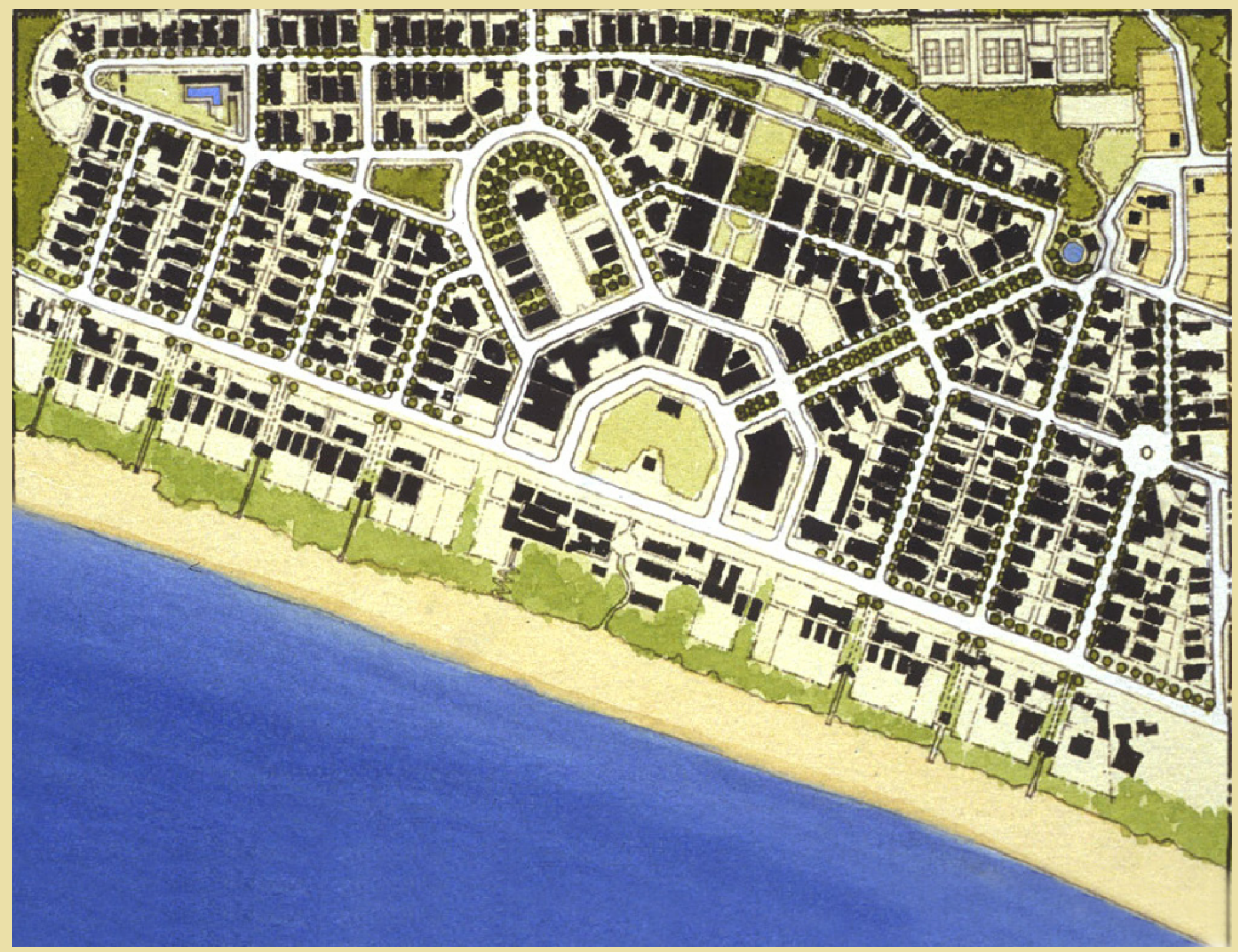

Fig. 10. Plano ilustrativo del diseño urbano de Seaside. 


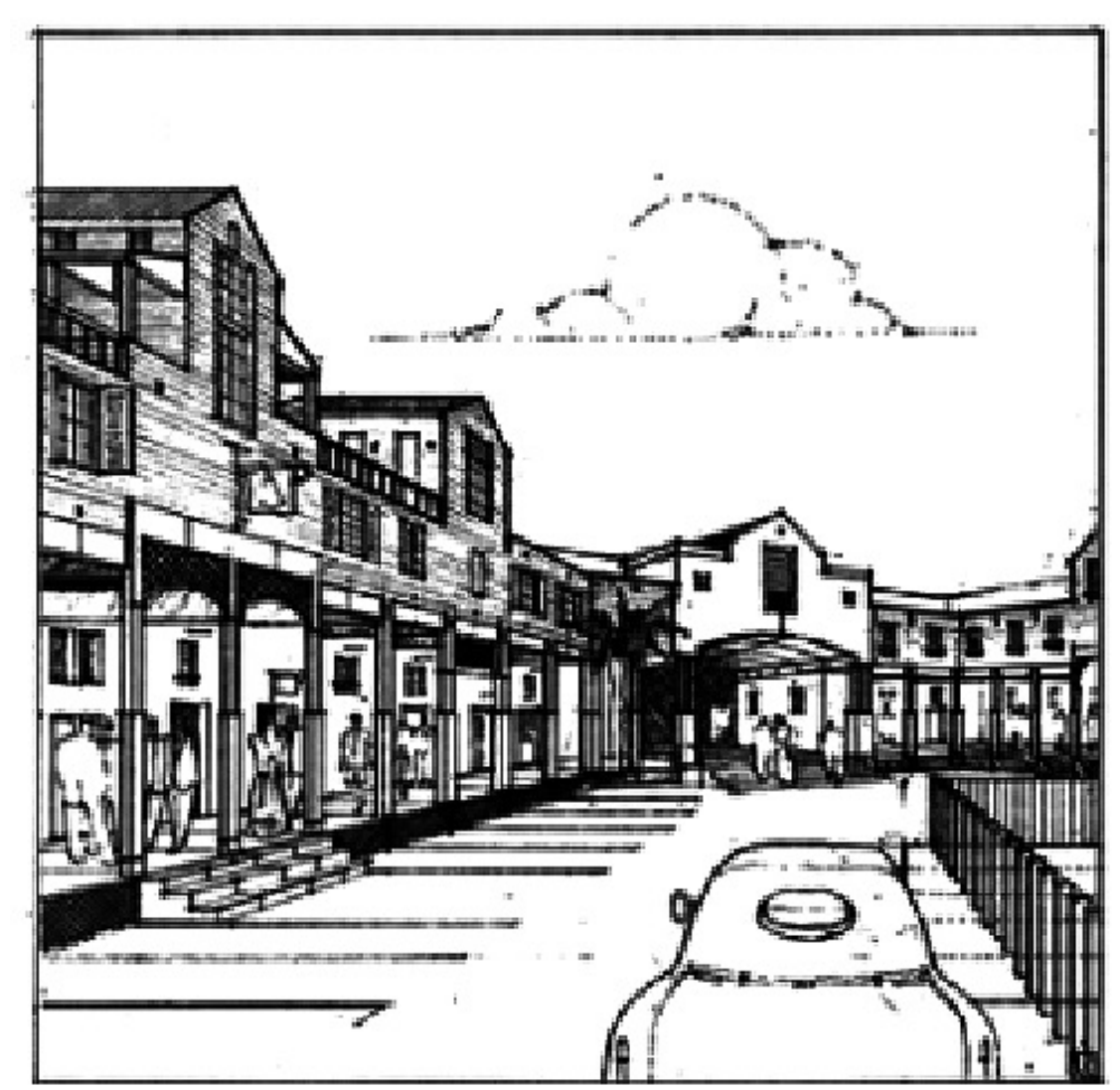

Edificaciones TIPO 1

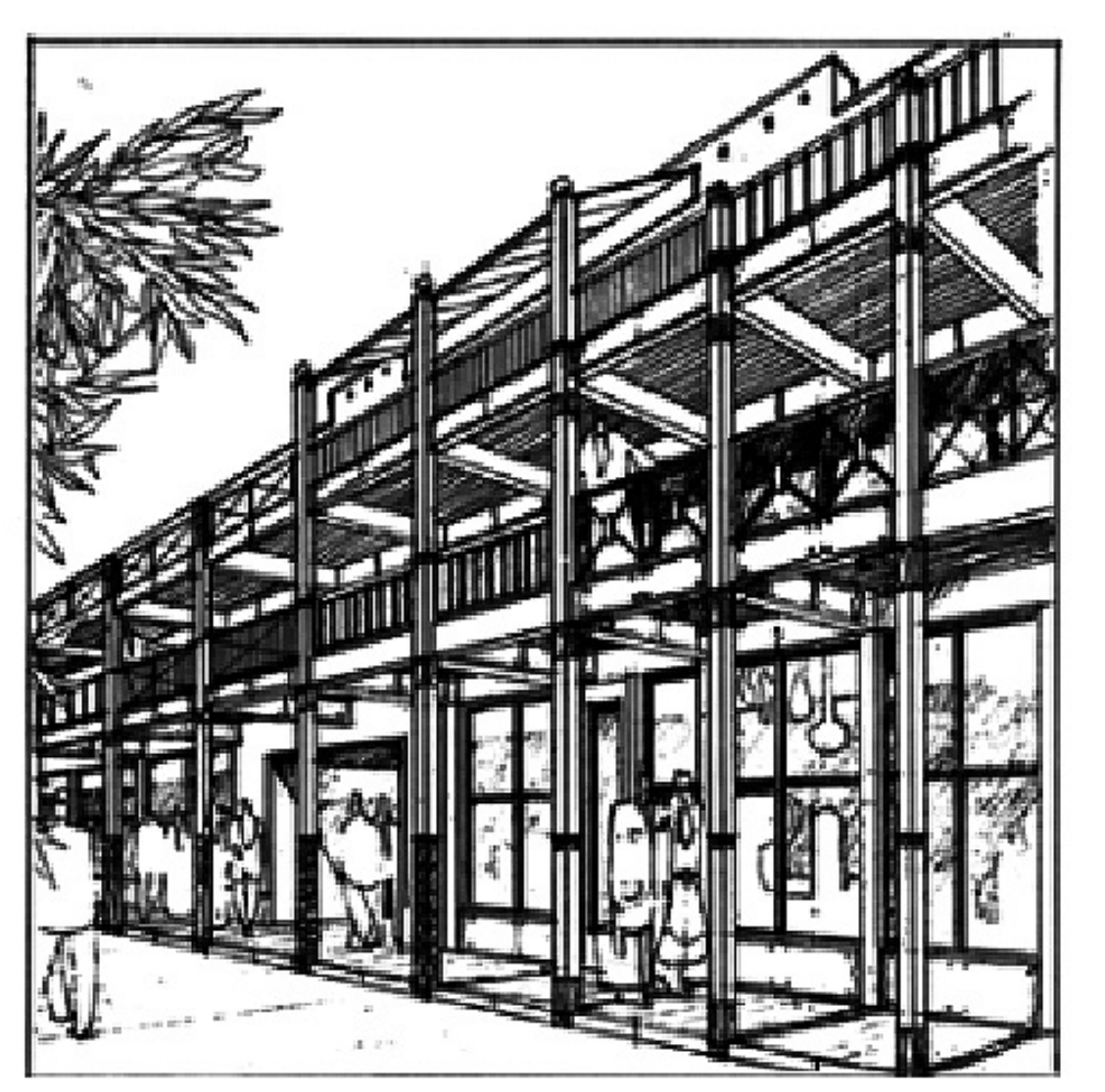

Edificaciones TIPO 2

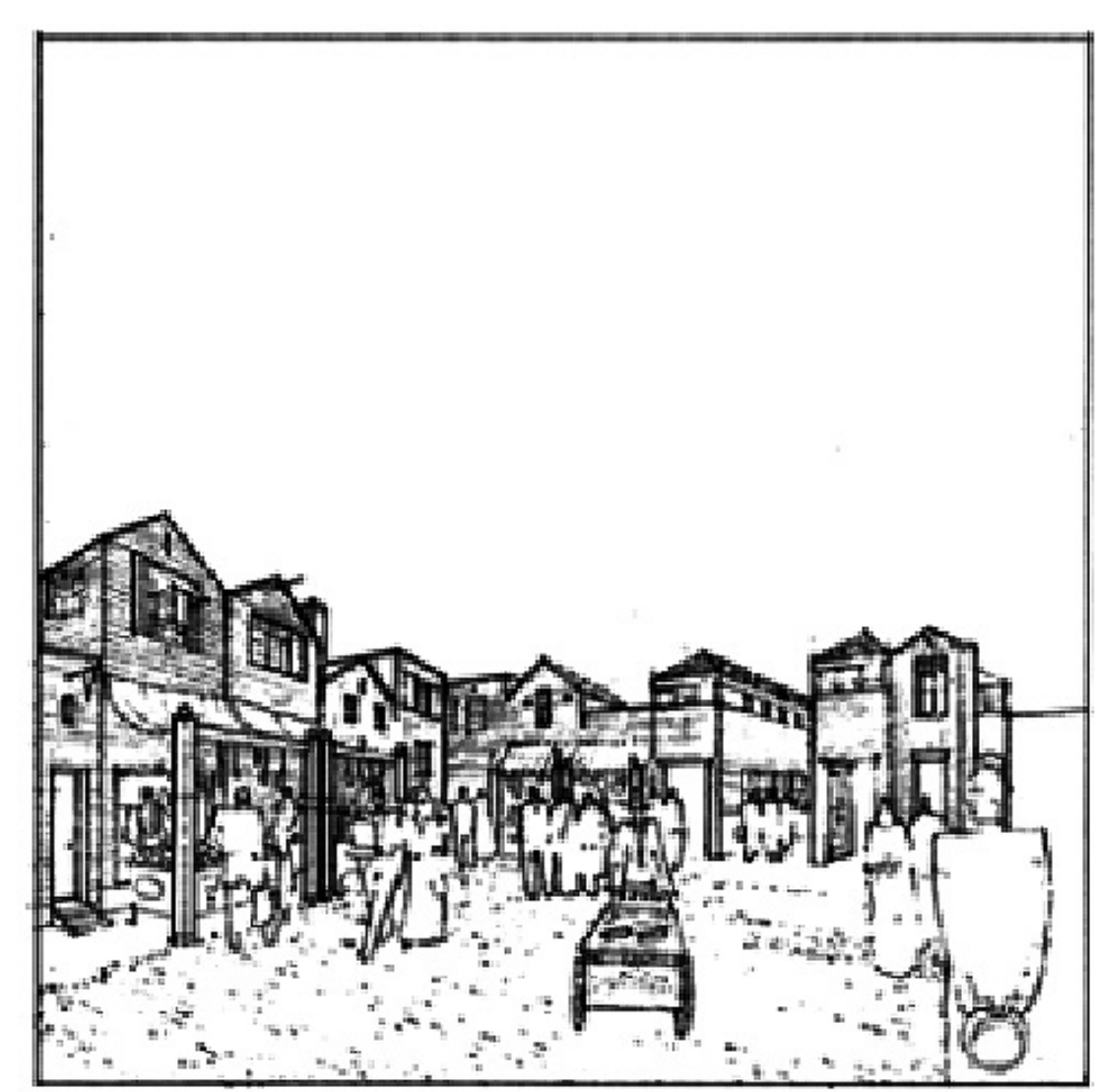

Edificaciones TIPO 3

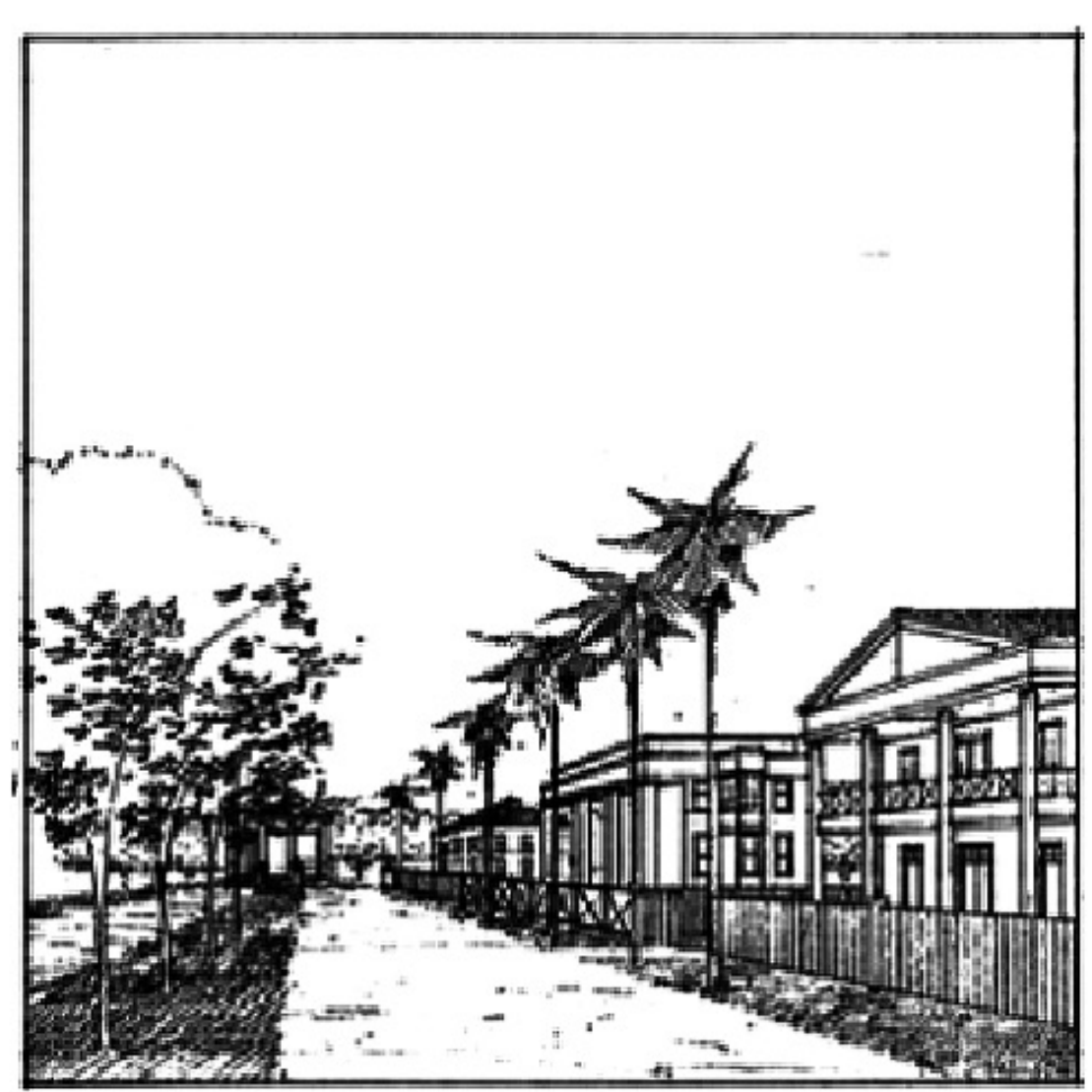

Edificaciones TIPO 4 


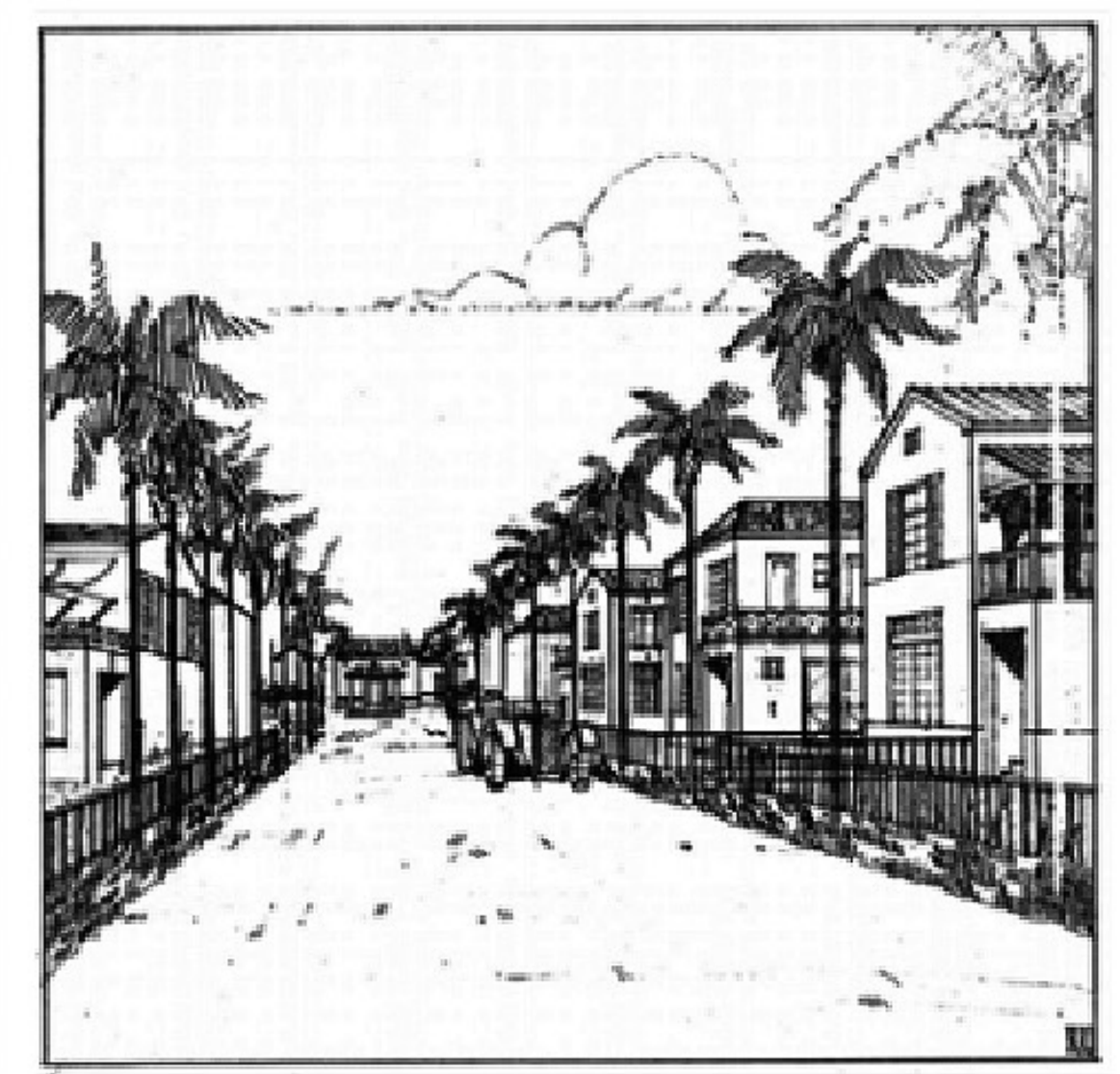

Edificaciones TIPO 7

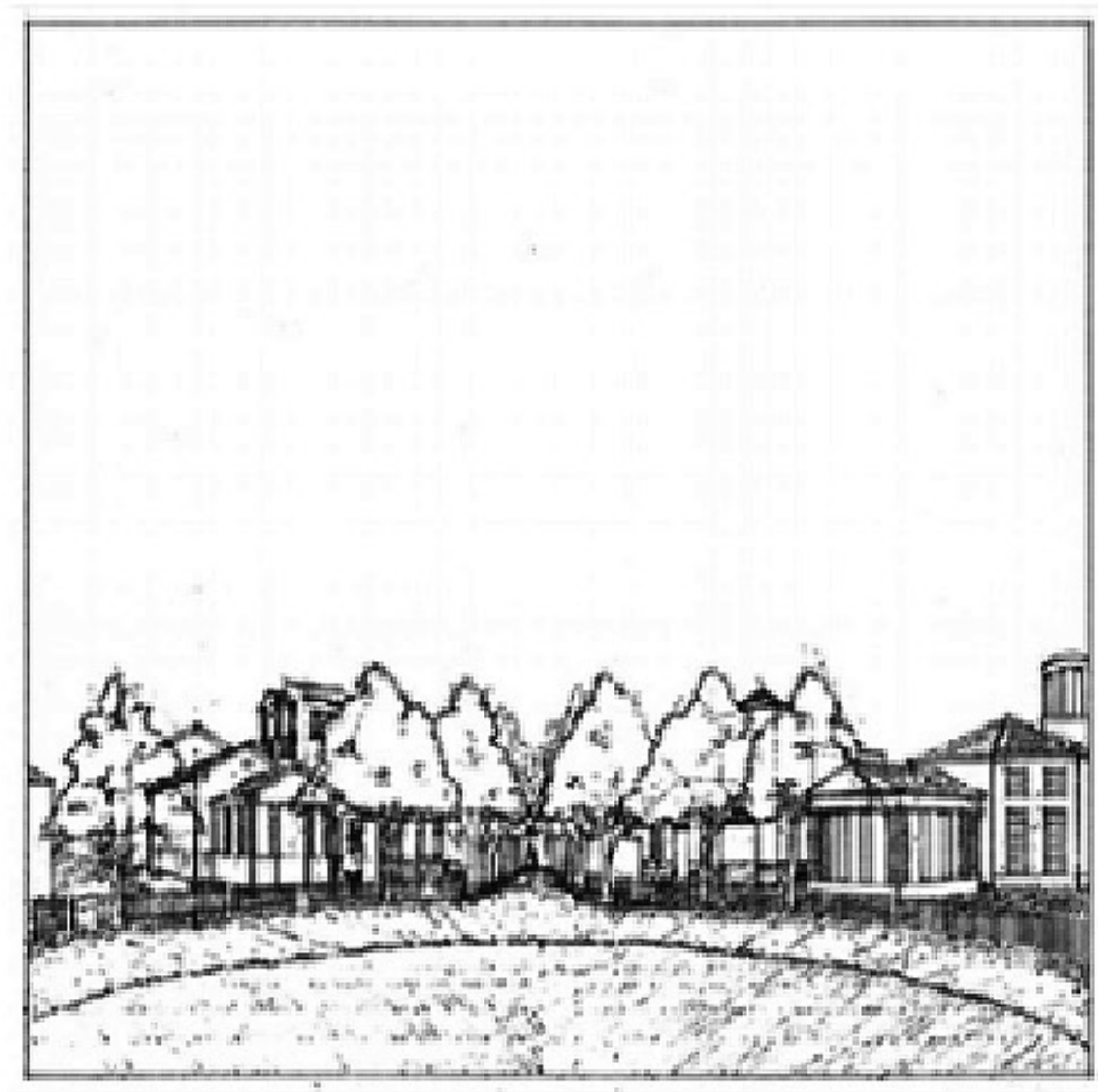

Edificaciones TIPO 8 


\section{YARD}

An area left free of structures more than 2 feet in height.

\section{PORCH}

An unglazed

roofed structure

An unglazed

cantilivered structure.

\section{OUT-BUILDING}

An auxiliary structure

located within a yard area.

\section{PARKING}

An open area no less than $10 \mathrm{ft}$. by $20 \mathrm{ft}$. with a minimun $10 \mathrm{ft}$. wide

continuous access from the street.

\section{HEIGHT}

The vertical distance between the average enfronting street elevation and a specified point on a structure.

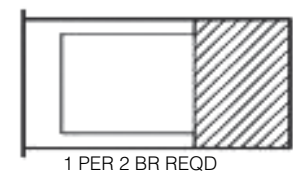

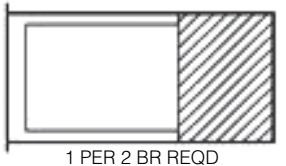
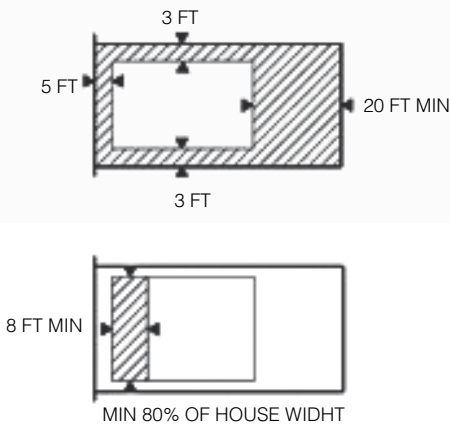

PER 2 BR REQD

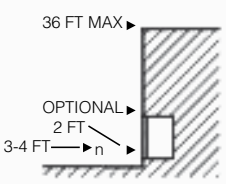

None

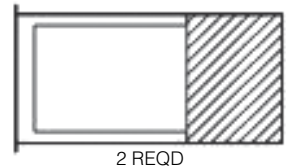

LOTS 13 - 18

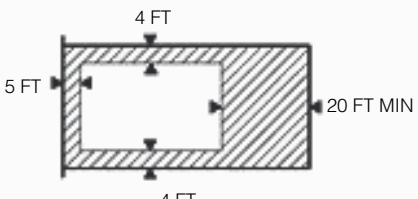

$4 \mathrm{FT}$

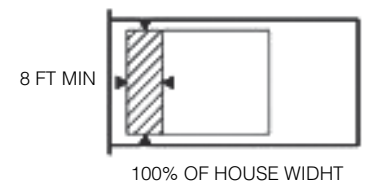

100\% OF HOUSE WIDHT

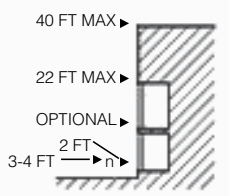

. Front facade faces the croquet Lawn. . Al bu shall be centered on front facade. same shade of white.

4. Shutters, if any shall be gloss black.

5. Lot 13: building shall be centered on the pool.

\section{SPECIFICATIONS}

1. The street facade shall extend along the front yard line a minimum of the designated percentage of the lot width.

Wood fences shall, be built along the street and footpath property lines except in types I and II.

1. The porch or balcony shall extend in width a minimun of the designated percentage of the street arcade.

2. The front porch or balcony shall be the minimum designated depth.

3. The window proportion shall be square or vertical.

1. No outbuildings allowed

1. The specified number of parking spaces shall be provided within the area designated.

2. Trucks, boats, campers and trailers, airstream

types excepted, shall be parked in rear yards only.

1. Minimun and maximum building heights shall be as designated.

2. There shall not height limit on structures or portions of structures with a footprint of less than $200 \mathrm{sq}, \mathrm{ft}$.

3. The principal roof shall be a symmetrical gable or hip with a slope of 4 in 12 .

4. A shed roof small have a pitch of 3 in 12 and be permitted only when attached to a principal roof or wall.

5. A flat roof shall be permitted only as a habitable deck enclosed by a continous balustrade or papapet.

1. All building plans shall be submitted to the seaside administration for comformity to the code.

2. Variances of the code shall be granted on the basics of architectural merit.

3. All buildings shall conform to the approved materials list.

4. Architects shall be selected by the Seaside Administration.

5. The definitions and specifications of the Seaside Urban Code shall apply.

Urban Code shall apply. 6. The Seaside
shall apply.
Fig. 12. Código urbano de Seaside.

Fuente: University of Notre Dame (s.f.) 


\section{Barcelona de Indias, Cartagena}

Si bien en Colombia se ha hecho evidente un fenómeno creciente de urbanización desde principios del siglo XX, acrecentado desde la segunda mitad, catalizado por la violencia y sostenido en los primeros tres lustros del siglo XXI, éste no puede compararse cabalmente con la realidad de las ciudades norteamericanas, tanto en las tendencias de densificación de los centros urbanos, como en el cada vez más notorio fenómeno de suburbanización de las principales metrópolis del país. Sin embargo, nuevos desarrollos residenciales de baja densidad que emulan características del nuevo urbanismo se han ubicado en las periferias de las principales ciudades, especialmente aquellas en las que se ha ido consolidando recientemente un mercado inmobiliario lo suficientemente grande y próspero como para apostarle a la producción de grandes volúmenes de soluciones residenciales para clase media alta que ya cuenten con una vivienda en la ciudad y que aspiren a una segunda vivienda, en la mayoría de los casos, con fines lúdicos o vacacionales.

Cartagena de Indias, con aproximadamente un millón de habitantes, se posiciona dentro de las seis aglomeraciones urbanas más importantes de
Colombia, y dado su potencial turístico, el mercado inmobiliario ha experimentado un notorio auge en los últimos años, especialmente en el ámbito residencial sobre la autopista Cartagena - Barranquilla. En este eje vial de suma importancia a nivel regional, a unos 20 $\mathrm{km}$ del centro de la ciudad, se ubica Barcelona de Indias, un proyecto en el que se emulan aspectos estéticos de la Ciudad Jardín, planteando varios desarrollos residenciales internos con distintas tipologías de vivienda, acceso controlado, cercanos a un centro comercial, el litoral Caribe y a instituciones privadas de educación básica y universitaria.

Barcelona de Indias se promociona y ejecuta en distintas fases; cada una de ellas es un desarrollo en polígono, es decir, cerrado por muros en su contorno, con acceso controlado, restringiendo el ingreso a los que no sean propietarios del condominio, por lo tanto, su malla vial interna no tiene una integración plena con la trama urbana pública y la articulación entre las distintas fases o proyectos se da en torno a una serie de parques y reservorios de agua. Los usos comerciales no se mezclan directamente con los residenciales, sino que estos se ubican en un centro comercial externo a los distintos conjuntos residenciales, por lo tanto, el diseño no facilita el acceso peatonal a estos usos desde sus viviendas. 


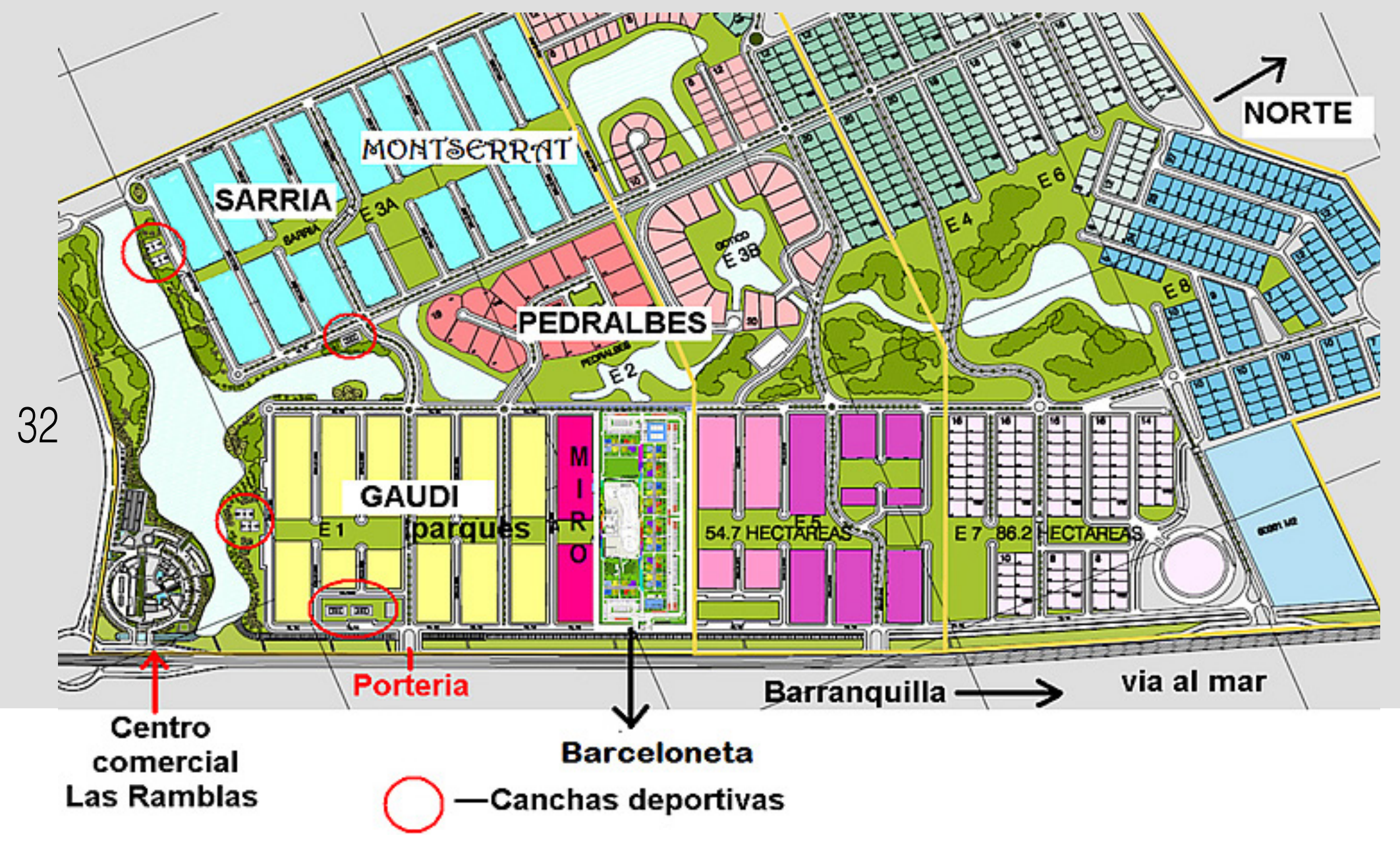

Fig. 13. Etapas y proyectos de Barcelona de Indias en Cartagena.

Fuente: www.cartagenainmuebles.com 


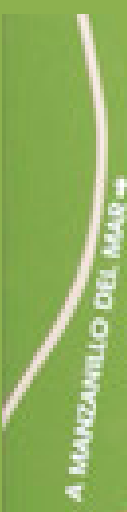

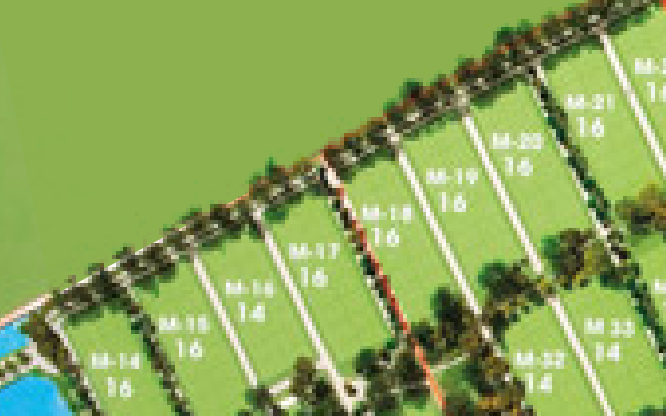

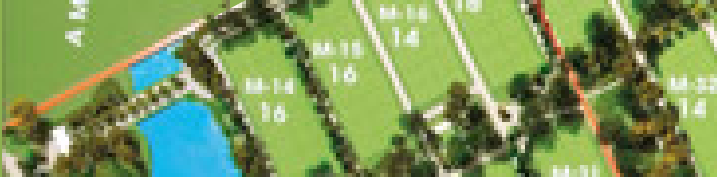

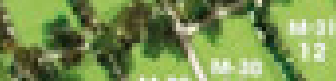

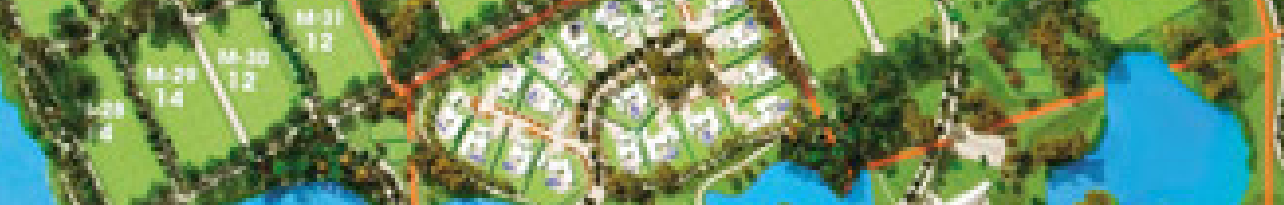

$\cos ^{2} \mathrm{x} / \mathrm{s}$

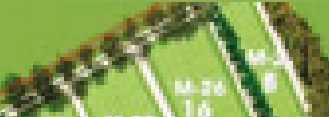
in

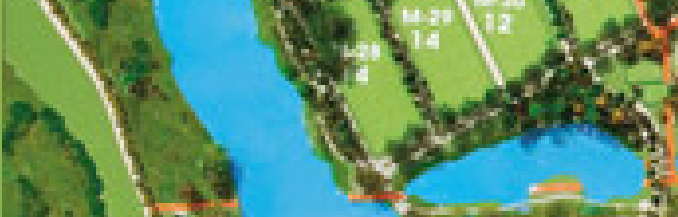

T.
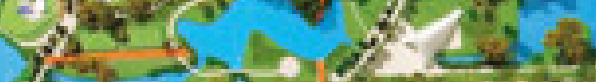
P.1.

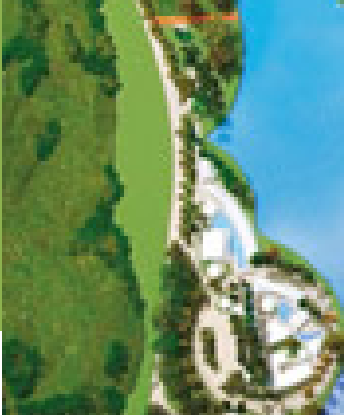

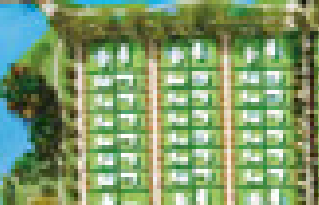
$x=2-m, 2 x+2$

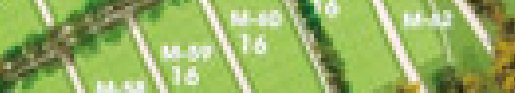

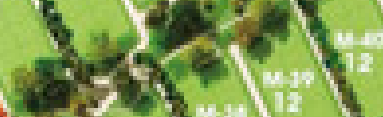
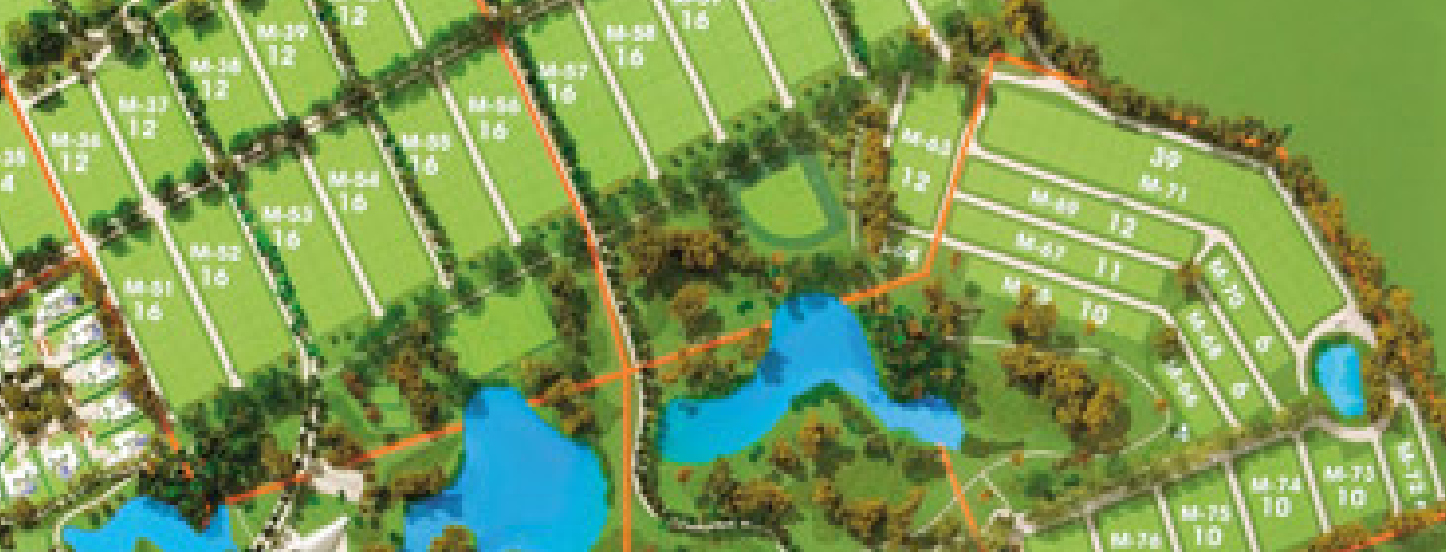

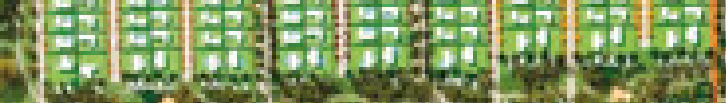

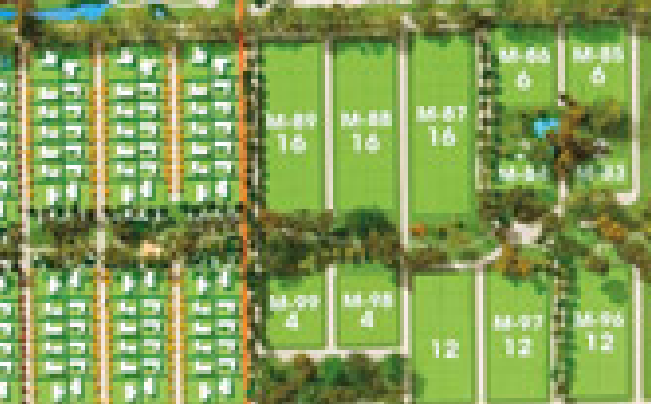

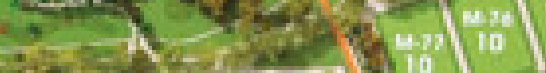
$42 x=5$

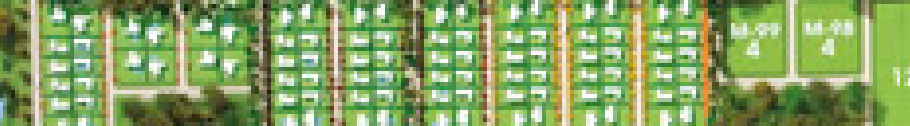

Fig. 14. Plano publicitario de Barcelona de Indias.

Fuente: www.constructorabarajas.com 


\section{$\circ \bigcirc$ PLANOS ○০}

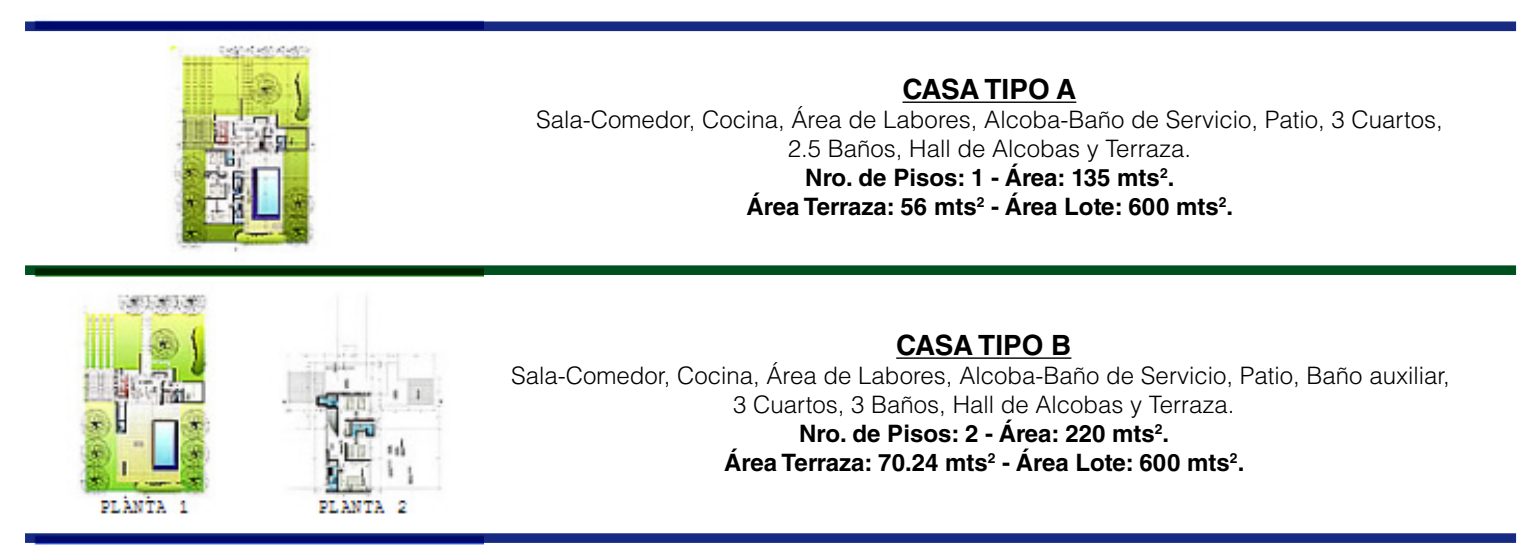

\section{CASA TIPO B-B}

Sala-Comedor, Cocina, Área de Labores, Alcoba-Baño de Servicio, Patio, 3 Alcobas, 3.5 Baños, Hall de Alcobas y Terraza.

Nro. de Pisos: 1 - Área: $152 \mathrm{mts}^{2}$. Área Lote: $600 \mathrm{mts}^{2}$.

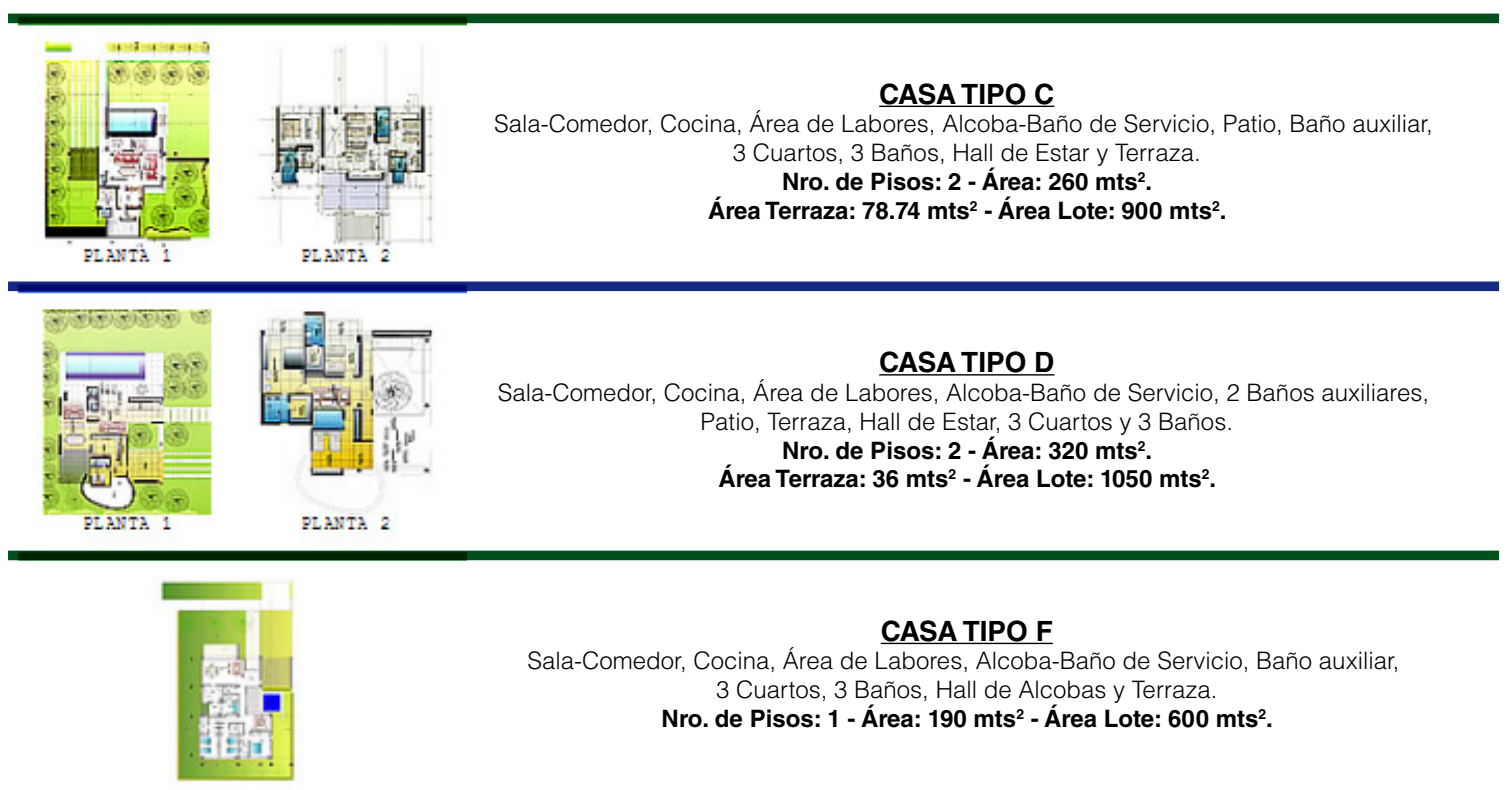

Fig. 15. Tipologías de vivienda propuestas por la empresa promotora del proyecto.

Fuente: www.cartagenainmuebles.com 
Tabla 1.

Comparativo de los modelos estudiados a partir de los principios rectores del 'New Urbanism'.

\begin{tabular}{|c|c|c|c|}
\hline \multicolumn{2}{|c|}{$\begin{array}{l}\text { PRINCIPIO DEL } \\
\text { 'NEW URBANISM' }\end{array}$} & SEASIDE - FL. & BARCELONA DE INDIAS \\
\hline 1 & PEATONALIZACIÓN & $\begin{array}{l}\text { El diseño permite que pueda accederse } \\
\text { a equipamientos de diversos usos } \\
\text { caminando desde la vivienda. }\end{array}$ & $\begin{array}{l}\text { Para acceder a usos comerciales } \\
\text { o educativos es necesario que los } \\
\text { residentes salgan de sus vecindarios y } \\
\text { se desplacen distancias considerables. }\end{array}$ \\
\hline 2 & CONECTIVIDAD & $\begin{array}{l}\text { La malla vial está abierta y conectada } \\
\text { con la red vial pública. Existen senderos } \\
\text { peatonales de corta distancia. }\end{array}$ & $\begin{array}{l}\text { La malla vial está cerrada a la red vial } \\
\text { pública; existen senderos peatonales } \\
\text { continuos entre varias manzanas. }\end{array}$ \\
\hline 3 & MEZCLA DE USOS & $\begin{array}{l}\text { Se evidencia mezcla de usos } \\
\text { residenciales con comerciales, } \\
\text { educativos, recreativos, etc. }\end{array}$ & $\begin{array}{l}\text { Al interior del proyecto, los usos son } \\
\text { predominantemente residenciales; para } \\
\text { acceder a educación y comercio se } \\
\text { requiere salir del vecindario. }\end{array}$ \\
\hline 4 & $\begin{array}{l}\text { DIVERSIDAD } \\
\text { TIPOLÓGICA } \\
\text { RESIDENCIAL }\end{array}$ & $\begin{array}{l}\text { El código urbano del proyecto promovía } \\
\text { diversas tipologías de edificaciones. }\end{array}$ & $\begin{array}{l}\text { La empresa desarrolladora promueve } \\
\text { diseños preestablecidos de vivienda } \\
\text { con diversas tipologías. }\end{array}$ \\
\hline 5 & $\begin{array}{l}\text { DISEÑO DE } \\
\text { CALIDAD }\end{array}$ & Cumple con criterios de estética urbana. & $\begin{array}{l}\text { Cumple con criterios de estética } \\
\text { urbana. }\end{array}$ \\
\hline 6 & $\begin{array}{l}\text { ESTRUCTURA } \\
\text { VECINAL } \\
\text { TRADICIONAL }\end{array}$ & $\begin{array}{l}\text { La configuración de sus espacios } \\
\text { públicos y la relación con sus } \\
\text { equipamientos cívicos le confiere } \\
\text { calidad de tradicional al vecindario. }\end{array}$ & $\begin{array}{l}\text { Al ser un desarrollo privado de acceso } \\
\text { restringido, y además no contar con } \\
\text { equipamientos cívicos típicos, no } \\
\text { cumple con el criterio de ser un barrio } \\
\text { tradicional. }\end{array}$ \\
\hline 7 & DENSIFICACIÓN & $\begin{array}{l}\text { Se promueve la vivienda unifamiliar en } \\
\text { todo el vecindario. }\end{array}$ & $\begin{array}{l}\text { Una proporción del proyecto se destina } \\
\text { a edificios de apartamentos. }\end{array}$ \\
\hline 8 & $\begin{array}{l}\text { TRANSPORTE } \\
\text { VERDE }\end{array}$ & $\begin{array}{l}\text { Promueve el tránsito 'verde' al interior } \\
\text { del vecindario a través del alquiler de } \\
\text { bicicletas públicas. }\end{array}$ & $\begin{array}{l}\text { Permite el tránsito en bicicleta y } \\
\text { peatonal al interior del vecindario. } \\
\text { No hay rutas de transporte público } \\
\text { distritales hacia el proyecto. }\end{array}$ \\
\hline 9 & SOSTENIBILIDAD & $\begin{array}{l}\text { El enfoque de sostenibilidad se basa en } \\
\text { la generación de relaciones complejas } \\
\text { sobre la mezcla de usos. }\end{array}$ & $\begin{array}{l}\text { Es un barrio tradicional en cuanto a } \\
\text { consumo energético. }\end{array}$ \\
\hline 10 & CALIDAD DE VIDA & $\begin{array}{l}\text { En su interior se ubican equipamientos } \\
\text { que permiten desarrollar actividades } \\
\text { culturales y recreativas. }\end{array}$ & $\begin{array}{l}\text { El vecindario requiere complementarse } \\
\text { con equipamientos culturales y plazas } \\
\text { públicas que promuevan una mayor } \\
\text { integración social. }\end{array}$ \\
\hline
\end{tabular}




\section{Conclusiones}

Se puede concluir que el 'New Urbanism' es un movimiento que se gestó en medio del contexto coyuntural de la crisis del petróleo de los años 70, coincidiendo casi con el descenso del auge del funcionalismo urbano-arquitectónico y abriendo paso al posmodernismo como una alternativa menos ruda que lo plasmado por el movimiento moderno en términos estéticos y conceptuales (Blasco, 2015). Los autores que dieron el soporte teórico lo promovieron como un nuevo paradigma urbano que se regía por un conjunto de principios o ideales, como la concepción de comunidades con bordes urbanos claramente delimitados, más compactas y densas que los desarrollos tradicionales, cuyo diseño, además, promoviera la continuidad de los ecosistemas, tanto en los ámbitos urbanos como en los rurales, que impulsara la diversificación edilicia, permitiendo la mezcla tipológica de viviendas en un mismo sector, con lo cual se podría facilitar la peatonalización de los barrios, el uso más asiduo de la bicicleta y el transporte público, reduciendo, por tanto, el uso del automóvil y el impacto en el ambiente en términos de emisiones de gases efecto invernadero (Kelbaugh, 1997).

Con los años, el nuevo urbanismo ha evolucionado en su institucionalidad y la producción documental para estructurar los criterios que rigen las intervenciones urbanas y arquitectónicas que se enmarcan dentro de esta etiqueta. Como herederos del paradigma ecologista del postmodernismo de finales de siglo, aparece el USGBC con los sistemas estandarizados de calificación de las construcciones verdes, como herra- mienta de clasificación de las propuestas que se acogen a los principios rectores del nuevo urbanismo y, a su vez, garante de la objetividad con la que, la siempre presente institucionalidad, etiqueta los productos inmobiliarios que cada vez más llegan al mercado del diseño, construcción y promoción de proyectos urbano-arquitectónicos.

Actualmente, a nivel global, se implementan varios sistemas estandarizados de calificación para construcciones verdes, como el BREEAM en Reino Unido, el DGNB en Alemania, el GREEN STAR en Australia, Nueva Zelanda y Sudáfrica, los ICODES de China, el GREEN MARK de Singapur o el CASBEE en Japón, entre otros, pero en ámbitos sudamericanos, como el caso de Colombia, se ha adoptado el LEED como referente para incursionar de forma más estructurada en la construcción sostenible. (Lam, Zhang, Wang, Dong y Zhang, 2016) (Say y Wood, 2008) (Ahmed, 2014).

El campo de la construcción verde y los sistemas de valoración que orbitan entorno a ella está escasamente difundido o afianzado en el mercado inmobiliario colombiano, pero crece su presencia de forma paulatina. Es por ello que resulta pertinente añadir al debate una profunda reflexión acerca del rumbo que ha tomado el nuevo urbanismo y la correspondencia con la esencia conceptual más primigenia que apela por lo ambiental, pero que, en la actualidad, en muchos proyectos promueve la dispersión urbana y los desarrollos en baja densidad, o por lo menos, difícilmente logran solventar las problemáticas de los centros urbanos preexistentes para mitigar las tendencias de dispersión en la ciudades norteamericanas. 
Finalmente, debido a que el proceso de urbanización en el entorno latinoamericano ha sido disímil a la realidad anglosajona, la versión hispana del 'New Urbanism', y, por supuesto, también la colombiana, no se muestra con todas las facetas que el modelo original expone, y la idea inicial de proponer comunidades pequeñas con límites bien determinados se ha traducido en urbanizaciones cerradas que propenden a la expansión con baja densidad y la segregación socio-espacial.

\section{REFERENCIAS}

Acevedo, H., Vasquez, A. \& Ramirez, D. (2012). Sostenibilidad: actualidad y necesidad en el sector de la construcción en Colombia. Gestión y Ambiente, 15(1), 105-118.

Ahmed, D. (2014). Rating Systems Awareness for Green Buildings Applications. International Refereed Journal of Engineering and Science (IRJES), 3(1), 53-64.

Appy, C. G. (2008). La guerra de Vietnam. (M. Aldalur Balbas, Trad.) Barcelona, Cataluña, España: Crítica.

Arroyo, M. (2001). La contraurbanización: un debate metodológico y conceptual sobre la dinámica de las áreas metropolitanas. Scripta Nova: Revista Electrónica de Geografía y Ciencias Sociales, (5), 79-104.

Blasco, J. A. (2015). Urban Networks. Recuperado el 01 de agosto de 2017, de http:// urban-networks.blogspot.com/2015/04/ La-Vision-Del-New-Urbanism-Mirar-Al. Html
Busquets, J. y Correa, F. (2006). Ciudades: 10 formas. Una nueva mirada hacia el proyecto urbanístico. (Primera Reimpresa Ed.). (J. Busquets y F. Correa, Eds.) Cambridge, Massachusetts, Estados Unidos: Harvard University.

Camagni, R. (2004). Economía urbana. (V. Galletto, Trad.) Barcelona: Antoni Bosch Editor, S.A.

Congress for the New Urbanism - CNU, (2001). Carta del nuevo urbanismo. Recuperado de https://www.cnu.org/ sites/default/files/cnucharter_spanish.pdf

Congress for the New Urbanism - CNU. (2013). Charter of the New Urbanism (2 Ed.). (E. Talen, Ed.) New York, New York, United States: Mcgraw-Hill Education.

Duany, A., Sorlien, S. y Wright, W. (2003). Smartcode Version 9.2. Independent Publishing Platform. Obtenido de: https://www.dpz.com/uploads/Books/ SmartCode-v9.2.pdf

Glaeser, E. (2011). El triunfo de las ciudades. Cómo nuestra mejor creación nos hace más ricos, más inteligentes, más ecológico, más sanos y más felices (1 Ed.). (F. Corriente Basús, Trad.) Madrid, España: Taurus.

Gunn, P. (2005). O New Urbanism E O Revival Escapista De Mercado. Risco: Revista De Pesquisa Em Arquitetura E Urbanismo, (2), 105-107.

Heins, M. (2015). Finding common ground between new urbanism and landscape urbanism. Journal of Urban Design, 20(3), 293-302. 
Jacobs, J. (1961). Muerte y vida de las grandes ciudades americanas (2 Ed.). (J. V. Campo Blanco, Ed., Á. Abad y A. Useros, Trads.) Madrid, España: Capitán Swing Libros.

Kelbaugh, D. (1997). The New Urbanism. Journal of Architectural Education, 51(2), 142-144.

Krier, R. (1976). El espacio urbano: proyectos de Stuttgart. Barcelona: Gustavo Gili.

Lam, K. P., Zhang, R., Wang, H., Dong, B., \& Zhang, R. (2016). Development of web-based information technology infrastructures and regulatory repositories for green building codes in China (Icodes). (X. YANG y J. ZENG, Eds.) Building Simulation, 6(2), 195-205.

Lynch, K. (1998). La imagen de la ciudad. Barcelona: Gustavo Gili.

Manrique, O. L. (2006). Fuentes de las economías de aglomeración: una revisión bibliográfica. Cuadernos de Economía, 25(45), 53-73.

newurbanism.org. (2017). Principles of Urbanism. Recuperado el 25 de octubre de 2017, de http://www.newurbanism. org/newurbanism/principles.html

Polèse, M. (1998). Economía urbana y regional. Introducción a la relación entre territorio y desarrollo (1 Ed.). (C. Barragán, S. Pérez Mendoza, Eds., G. Pérez Galicia y E. Pou Madinaveitia, Trads.) Cartago: Libro Universitario Regional.
Sablich, C. A. (2010). Aplicación de un modelo de dirección estratégica en épocas de crisis, estudio de caso: agroexportadora de Perú. Recuperado el 25 de octubre de 2017, de http://www. eumed.net/libros-gratis/2010e/837/ crisis\%20del\%20petroleo\%20de\%20 1979.htm

Say, C. y Wood, A. (2008). Sustainable rating systems around the world. CTBUH Journal, (2), 18-29.

Speck, J. (2013). Walkable city: how downtown can save America, one step at a time (1 Ed.). New York, New York, United States: Farrar, Straus And Giroux.

U. S. G. B. C. (2012). The Shipyard/Candlestick Point Scorecard. Recuperado el 3 de noviembre de 2017, de LEED ND: Plan V3 - LEED 2009. Disponible en: https://www.usgbc.org/projects/shipyardcandlestick-point?view=scorecard

University of Notre Dame. (s.f.). Explore the Seaside Plan. Recuperado el 27 de octubre de 2017, de The Seaside Research Portal: Archiving The First New Urban Community. Disponible en: https://seaside.library.nd.edu/ 